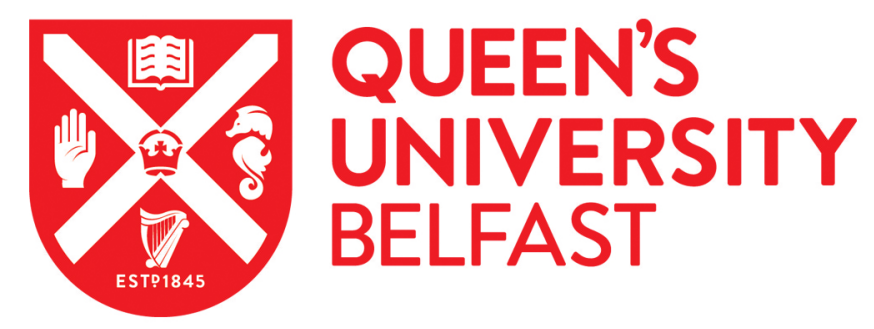

\title{
Lysine-derived, pH-sensitive and Biodegradable Poly(Beta-aminoester Urethane) Networks and Their Local Drug Delivery Behaviour
}

Tamer, Y., \& Chen, B. (2018). Lysine-derived, pH-sensitive and Biodegradable Poly(Beta-aminoester Urethane) Networks and Their Local Drug Delivery Behaviour. Soft Matter, 14(7), 1195-1209.

https://doi.org/10.1039/c7sm01886j

Published in:

Soft Matter

Document Version:

Peer reviewed version

Queen's University Belfast - Research Portal:

Link to publication record in Queen's University Belfast Research Portal

Publisher rights

(C) 2018 The Royal Society of Chemistry. This work is made available online in accordance with the publisher's policies. Please refer to any applicable terms of use of the publisher.

\section{General rights}

Copyright for the publications made accessible via the Queen's University Belfast Research Portal is retained by the author(s) and / or other copyright owners and it is a condition of accessing these publications that users recognise and abide by the legal requirements associated with these rights.

Take down policy

The Research Portal is Queen's institutional repository that provides access to Queen's research output. Every effort has been made to ensure that content in the Research Portal does not infringe any person's rights, or applicable UK laws. If you discover content in the Research Portal that you believe breaches copyright or violates any law, please contact openaccess@qub.ac.uk. 


\section{Soft Matter}

PAPER

Received 00th January 20xx, Accepted 00th January 20xx

DOI: $10.1039 / \times 0 \times x 00000 x$

www.rsc.org/

\section{Lysine-derived, pH-sensitive and Biodegradable Poly(Beta-aminoester Urethane) Networks and Their Local Drug Delivery Behaviour}

\begin{abstract}
Yasemin Tamer ${ }^{\mathrm{a}}$ and Biqiong Chen ${ }^{\mathrm{b}^{*}}$
In this study, a series of covalently crosslinked, L-lysine based poly(beta-aminoester urethane) (LPBAEU) networks with good biodegradability and $\mathrm{pH}$ sensitivity were reported. The effect of hydrophilic/hydrophobic character and diacrylate/amine molar ratio on the structure, swelling and degradation behaviour of the networks was investigated. Water transport mechanism and dynamic swelling behavior of LPBAEU networks were strongly affected by medium $\mathrm{pH}$, and swelling amounts up to $252.2 \%$ and $148.7 \%$ were observed in $\mathrm{pH} 5.6$ and $\mathrm{pH} 7.4$, respectively. It was found that water diffusion within the networks followed non-Fickian mechanism. The LPBAEU network with the highest diacrylate/amine molar ratio exhibited the highest tensile strength and Young's modulus. In vitro mass losses of networks showed that the degradation rate of LPBAEU networks can be adjusted from 4 to 14 days. LPBAEU networks also supported loading of doxycycline hyclate $(\mathrm{DH})$ and in vitro release studies demonstrated that release of $\mathrm{DH}$ from the networks was substantially hindered in the neutral $\mathrm{pH}$ environment, with $20.9-56.2 \% \mathrm{DH}$ release, whereas $\mathrm{DH}$ release was accelerated in mild acidic condition, with a release percentage of 36.6-99.6\%. The release data were fitted to different mathematical models and obtained results confirmed that these networks released $\mathrm{DH}$ in a non-Fickian mechanism. The results of this research support the idea that $\mathrm{pH}$-responsive LPBAEU networks may find potential applications in local drug delivery.
\end{abstract}

\section{Introduction}

In recent years, there has been an increasing amount of literature on the development of non-toxic, biodegradable and biocompatible chemically crosslinked polymer networks for applications such as tissue engineering, drug delivery, artificial skin and microdevices. ${ }^{1-4}$ Numerous polymeric biomaterials containing hydrolyzable bonds to achieve biodegradability have been developed to date including poly( $\varepsilon$-caprolactone), poly(lactic-co-glycolide), poly(propylene fumarate), poly(ethylene glycol) and poly(beta-aminoester). ${ }^{5-8}$ Among them, a considerable amount of literature has been published on poly(beta-aminoester) (PBAE) polymers that are completely biodegradable due to the hydrolysis of their ester bonds. ${ }^{9,10}$ In particular, degradable networks of these PBAE polymers that can be obtained with PBAEs having acrylate end groups, are highly attractive since their properties can be tuned by changing the diacrylate/amine molecules and their ratio to

${ }^{a}$ Department of Polymer Engineering, Yalova University, Yalova, 77100, Turkey. ${ }^{b}$ School of Mechanical and Aerospace Engineering, Queen's University Belfast, Ashby Building, Stranmillis Road, Belfast BT9 5AH. Email: b.chen@qub.ac.uk

Electronic Supplementary Information (ESI) available: See DOI: $10.1039 / x 0 x x 00000 x$ influence crosslinking density, hydrophilicity and degradation time. ${ }^{1,2,11-13}$ Yet, carcinogenic diacrylates are not generated through degradation since retro-Michael addition reaction is not observed. ${ }^{10}$

A current approach on biomaterials development has been on the use of different chemical functionalities in the same structure, in order to control the biocompatibility, degradation rate and mechanical properties for a specific application. ${ }^{8,14,15}$ As a result, many researchers have been focused on poly(ester urethane)s (PEUs) which are degradable with hydrolysable ester groups and have good thermal and mechanical properties due to the strong interactions between their amide groups. ${ }^{11,16}$ This flexible platform, combining the advantages of urethane and ester groups, has great potential as a biomaterial due to their non-toxicity, adjustable biodegradability and capability of creating ionic interactions with biomolecules. ${ }^{17}$

However, the adjustment of the properties of these PEUs to meet the biodegradability and biocompatibility requirements is an important issue and thus, novel poly(betaaminoester urethane)s (PBAEUs) can be synthesized by using diisocyanates generated from amino acids. ${ }^{18,19}$ To this end, there is an expanding interest on the usage of L-lysine diisocyanate (LLDI) in designing new polymers due to its potential hydrolytic degradable product, L-lysine, that is vital and more importantly not detrimental for our living 
system. ${ }^{20,21}$ Zhang and co-workers ${ }^{22,23}$ have developed a series of LLDI-based polyurethanes and found their non-toxic degradation products to be lysine, glycerol (or glucose) and $\mathrm{CO}_{2}$. Thus, the major advance of LLDI based carriers has been shown to have an easy evacuation by virtue of biodegradability after completing their function in the body. ${ }^{24,25}$

These crosslinked PBAEU polymer networks might be potential candidates for local drug delivery systems. In particular, local antibiotic delivery for periodontal diseases has become increasingly important during the past several years because of their efficiencies in minimizing the systemic exposure of antibiotics and maximizing the therapeutic efficiency as compared with the systemic delivery that causes adverse drug reactions by oral antibiotic intake. ${ }^{26-29}$ So far, different polymeric carriers exhibiting different release profiles for periodontal purposes have been designed in numerous forms such as microspheres, films, strips, rings, gels and injectable systems. ${ }^{30,31}$ However, only a few studies have focused on the usage of stimuli responsive devices for local antibiotic delivery in the treatment of periodontal diseases. The oral cavity has a $\mathrm{pH}$ range between 5.75 and $7.05,{ }^{26}$ and inflammation generally causes a relatively acidic environment with a $\mathrm{pH}$ value of 6 or less, ${ }^{32}$ so the usage of a delivery system with $\mathrm{pH}$ sensitivity can enhance the effectiveness of treatment. Recently, Yu et al. ${ }^{33}$ reported a new generation of $\mathrm{pH}$ sensitive and chitosan-based hydrogels and examined the in vitro antibiotic release profile of these hydrogels. Owing to the cationic nature, PBAEU polymers are capable of showing $\mathrm{pH}$-responsive behaviour resulting from protonation or deprotonation of their tertiary amino groups in the backbone, ${ }^{10,34}$ and therefore these $\mathrm{pH}$ sensitive networks seem to be good candidates for carrying antibiotics in periodontal therapy.

This work aimed to design novel $\mathrm{pH}$ sensitive, lysine based poly(beta-aminoester urethane) (LPBAEU) networks with adjustable swelling kinetics and biodegradability for local drug delivery applications. Firstly L-lysine containing urethane diacrylate (LDA) monomer was synthesised, and different types of crosslinkable LPBAEU macromers were obtained by using two different amine and diacrylate molecules and varying their molar ratio. Then, the residual acrylate groups of these macromers were chemically crosslinked via free radical polymerization. The effect of the changes in polymer structure and diacrylate/amine ratio on water diffusion mechanism, swelling and degradation profiles was investigated. Doxycycline hyclate (DH), an antibiotic against a wide spectrum of diseases caused by many gram-positive and gramnegative bacteria, was used as a model drug 26,35 to examine the drug delivery performance of these polymers for potential treatment of periodontal disease. Also, in-vitro $\mathrm{DH}$ release mechanism was explored in detail using various mathematical models.

\section{Experimental}

\section{Materials}

Poly(ethylene glycol) diacrylate (PEGDA) $\left(\bar{M}_{n}: 700\right)$, 4,4trimethylenedipiperidine (TMDP, 97\%), 2-aminoethanol (AE, 299.5\%), 2-hydroxyethyl acrylate (HEA, \%96), dibutyltin dilaurate (DBTL, 95\%), ammonium persulfate (APS, $\geq 98.0 \%$ ), $\mathrm{N}, \mathrm{N}, \mathrm{N}, \mathrm{N}$-tetramethylethylenediamine (TEMED, $\geq 99 \%$ ), phosphate buffered saline (PBS) tablets and lipase enzyme form porcine pancreas were purchased from Sigma Aldrich. LLysine ethyl ester diisocyanate, (LLDI, 97\%) and doxycycline hyclate were supplied from Alfa-Aeser. All the solvents, chloroform $\left(\mathrm{CHCl}_{3}\right)$, diethyl ether, dichloromethane (DCM), dimethyl sulfoxide (DMSO), tetrahydrofuran (THF) and hexane, were of analytical grade and obtained from Sigma-Aldrich and used as received.

\section{Synthesis}

The synthesis of macromers was performed in two steps. For the first step, $1.16 \mathrm{~g} \mathrm{HEA}$ and $0.0126 \mathrm{~g}$ DBTL were dissolved in $20 \mathrm{ml} \mathrm{CHCl}_{3}$ and exposed to three 10-minute cycles of vacuum drying followed by nitrogen purging. The mixture was heated to $60{ }^{\circ} \mathrm{C}$ after the addition of $1.13 \mathrm{~g} \mathrm{LLDI}$ and reflux under $\mathrm{N}_{2}$ for 4 hours. The majority of the solvent was evaporated in a rotary evaporator until approximately $10 \mathrm{ml} \mathrm{CHCl}_{3}$ left and the reaction mixture was precipitated in hexane. The obtained diacrylate product, LDA, was dried under vacuum for 2 days.

The acrylate terminated LPBAEU macromers were obtained by Michael type addition step-wise polymerization between the mixture of LDA and PEGDA and AE or TMDP as reported previously. ${ }^{36}$ In a typical experiment, a mixture of $2.2 \mathrm{~g}$ LDA and $1.54 \mathrm{~g}$ PEGDA, and $0.36 \mathrm{~g} \mathrm{AE}$ monomer were dissolved separately in THF. The diacrylates containing solution was placed into a glass vial and the amine solution was added dropwise and the polymerization was carried out under magnetic stirring at $55^{\circ} \mathrm{C}$ for 3 days. The reaction mixture was precipitated into diethyl ether to remove any unreacted monomer and the obtained macromer was dried in a desiccator connected to a vacuum pump for 3 days. Different macromers were obtained by changing the type of amine molecule and the ratio of diacrylate to amine (Table 1 ).

The LPBAEU networks were obtained by using a chemically initiated free radical polymerization using APS and TEMED as an initiator and catalyst, respectively. First, macromer was dissolved in ethanol at a concentration of $75 \mathrm{wt} \%$, and the mixture of $2 \mathrm{wt} \%$ APS (dissolved in $0.5 \mathrm{ml}$ ethanol) and $2 \mathrm{wt} \%$ TEMED (based on macromer weight) were added to this solution. The mixture was transferred to a non-sticky mold after being sonicated for $30 \mathrm{~s}$, and kept at room temperature for 2 days and further 2 days under vacuum at $40{ }^{\circ} \mathrm{C}$ to realize crosslinking and evaporate the solvent. Specimens with a dimension of $10 \mathrm{~mm} \times 10 \mathrm{~mm}$ and a thickness of $0.44 \pm 0.08$ $\mathrm{mm}$ were cut from the films to be used in swelling, degradation and drug release studies. 
Table 1 The theoretical composition, molecular weight, sol fraction and contact angle of LPBAEU networks*

\begin{tabular}{|c|c|c|c|c|c|c|c|c|c|c|c|}
\hline \multirow[t]{2}{*}{ Sample } & \multicolumn{4}{|c|}{ Feed ratio / \% } & \multirow{2}{*}{$\begin{array}{l}\mathrm{D}: \mathrm{A} \\
\text { ratio }\end{array}$} & \multirow{2}{*}{$\begin{array}{c}\text { Yield } \\
/ \%\end{array}$} & \multicolumn{3}{|c|}{$\begin{array}{c}\text { Molecular weight } \\
/ \mathrm{g} \mathrm{mol}^{-1}\end{array}$} & \multirow{2}{*}{$\begin{array}{c}\text { Sol } \\
\text { fraction } \\
/ \%\end{array}$} & \multirow{2}{*}{$\begin{array}{c}\text { Contact } \\
\text { angle } \\
/^{\circ}\end{array}$} \\
\hline & LDA & PEGDA & AE & TMDP & & & $\bar{M}_{w}$ & $\bar{M}_{n}$ & PDI & & \\
\hline LPBAEU-A1 & 27.28 & 27.28 & 45.44 & 0 & $1.2: 1$ & 89.6 & 7340 & 2996 & 2.45 & $8.2 \pm 0.3$ & $29.8 \pm 8.6$ \\
\hline LPBAEU-A2 & 29.17 & 29.17 & 41.66 & 0 & 1.4:1 & 91.2 & 6180 & 3936 & 1.57 & $3.7 \pm 0.9$ & $45.5 \pm 6.7$ \\
\hline LPBAEU-T1 & 27.28 & 27.28 & 0 & 45.44 & $1.2: 1$ & 87.4 & 8350 & 4217 & 1.98 & $13.5 \pm 0.7$ & $48.6 \pm 2.1$ \\
\hline LPBAEU-T2 & 29.17 & 29.17 & 0 & 41.66 & $1.4: 1$ & 88.1 & 7125 & 3345 & 2.13 & $6.4 \pm 0.2$ & $69.3 \pm 3.5$ \\
\hline
\end{tabular}

* The monomer and polymer names are abbreviated as described in the main text.

\section{Characterization}

\section{Chemical structure and physical properties}

Attenuated Total Reflectance Fourier Transform Infrared (ATRFTIR) analysis was done by using a Perkin Elmer Frontier FTIR spectrometer at a resolution of $4 \mathrm{~cm}^{-1}$, in the range of 4000 $600 \mathrm{~cm}^{-1}$. The structural elucidation of macromers was done by a $500 \mathrm{MHz}$ Bruker Proton Nuclear Magnetic Resonance $\left({ }^{1} \mathrm{H}-\right.$ NMR) spectrometer using $\mathrm{CDCl}_{3}$ and tetramethylsilane (TMS) as the solvent and internal reference, respectively. The molecular weights of the macromers were measured by Gel Permeation Chromatography (GPC) using a Hewlet-Packard 1090 HPLC with a differential refractive index detector and linear polystyrene standards to calibrate the columns. $\mathrm{CHCl}_{3}$ was used as eluent at a flow rate of $1.0 \mathrm{~mL} \mathrm{~min}-1$. The glass transition temperatures $\left(\mathrm{T}_{\mathrm{g}}\right)$ of LPBAEU networks were tested under nitrogen atmosphere with a Perkin-Elmer Diamond DSC at a rate of $10{ }^{\circ} \mathrm{C} \mathrm{min}^{-1}$ in the temperature range between -70 ${ }^{\circ} \mathrm{C}$ and $100{ }^{\circ} \mathrm{C}$. Second heating runs were used to obtain the $\mathrm{T}_{\mathrm{g}}$ values. Water-contact angle (CA) measurements of thin crosslinked LPBAEU films that were obtained on glass slides were taken by using a KRUSS DSA100 contact angle analyser image system. Distilled water was utilized as wetting liquid and five measurements were taken for each sample. To determine the sol fraction, the LPBAEU film specimens $(n=3)$ were immersed in DCM for $24 \mathrm{~h}$ and the values were calculated by dividing the mass loss between the initial and the final weight of the dry sample by the initial weight of the sample.

The swelling characteristics of the copolymer films were studied in PBS at two different $\mathrm{pH}$ values at room temperature. The swollen films were removed at various time points and immediately weighed after the water on the surface of the film was superficially removed with a tissue. Equilibrium state was considered when no further change was noticed in the weight of the swollen films and the swelling degree, SD, was calculated by using eqn (1):

$$
S D(\%)=\left(M_{t}-M_{0}\right) / M_{0} \times 100
$$

where $M_{t}$ and $M_{o}$ stand for the swollen weight of sample at time $t$ and the dry weight of sample, respectively. To obtain more reliable results three experiments were done for each sample. Also, swelling kinetics and water diffusion mechanism of the networks were determined by using the Voigt mode ${ }^{37}$ and Korsmeyer-Peppas model ${ }^{38}$ as described in Supporting Information.

Tensile tests were carried out on a Zwick/Roell test machine at a speed of $10 \mathrm{~mm} \mathrm{~min}^{-1}$, using a $50 \mathrm{~N}$ load cell at room temperature. Samples with a rectangular shape $(5 \mathrm{~mm} \times 50 \mathrm{~mm}$ ) were cut from crosslinked films and subjected to tension until failure. The ultimate tensile strength, Young's modulus (determined from the initial slope of the stress/strain curve) and elongation at break were calculated from three measurements for each sample.

\section{Degradation studies}

The in vitro degradation studies were performed with and without enzyme, lipase. The films with initial dry weights measured were immersed into $10 \mathrm{~mL} 0.05 \mathrm{M}$ PBS $(\mathrm{pH}$ 7.4) for hydrolytic degradation and $0.1 \mathrm{mg} \mathrm{mL}^{-1}$ lipase containing PBS solution for enzymatic degradation, and the degradation tests were carried out for 14 days in a shaker incubator (Stuart, S1500) at $100 \mathrm{rpm}$ and 37 ${ }^{\circ} \mathrm{C}$. The PBS/enzyme solution was replaced every $24 \mathrm{~h}$ to maintain the same level of enzymatic activity. At predetermined time intervals film samples were collected until they cannot be handled, and were gently washed with distilled water to remove PBS salts and kept under vacuum at $40{ }^{\circ} \mathrm{C}$ until a constant weight was reached to determine the remaining mass. Three parallel experiments were carried out for each network films and their mass change was recorded. The degradation ratio was determined by comparison of the weights of the film before and after degradation.

To determine the degradation products of LPBAEU-T1 network, the sample was immersed in distilled water and kept at $37^{\circ} \mathrm{C}$ in a shaker. After 7 days, the sample was taken out and aliquots of distilled water being in contact with the network were condensed in vacuum at $40^{\circ} \mathrm{C}$ to obtain degradation products. Then, FTIR-ATR spectrum of the resulting product was taken.

\section{Drug loading and release properties}

The drug loaded LPBAEU networks were obtained by soaking the copolymer films in doxycycline hyclate DMSO solution $\left(1 \mathrm{mg} \mathrm{ml}^{-1}\right)$ for 24 h. ${ }^{39}$ Then, the drug loaded films were washed with PBS to remove the surface adsorbed drug and dried under vacuum for $24 \mathrm{~h}$ at $40{ }^{\circ} \mathrm{C}$ and stored in desiccator for further study. For in vitro drug release studies, the $\mathrm{DH}$-loaded samples were placed in $10 \mathrm{~mL}$ PBS solution in neutral ( $\mathrm{pH} \mathrm{7.4)}$ and mild acidic ( $\mathrm{pH} \mathrm{5.6)} \mathrm{conditions} \mathrm{at} 37$ ${ }^{\circ} \mathrm{C}$ in a shaker incubator (100 rpm). At desired time points, $4 \mathrm{ml}$ of 


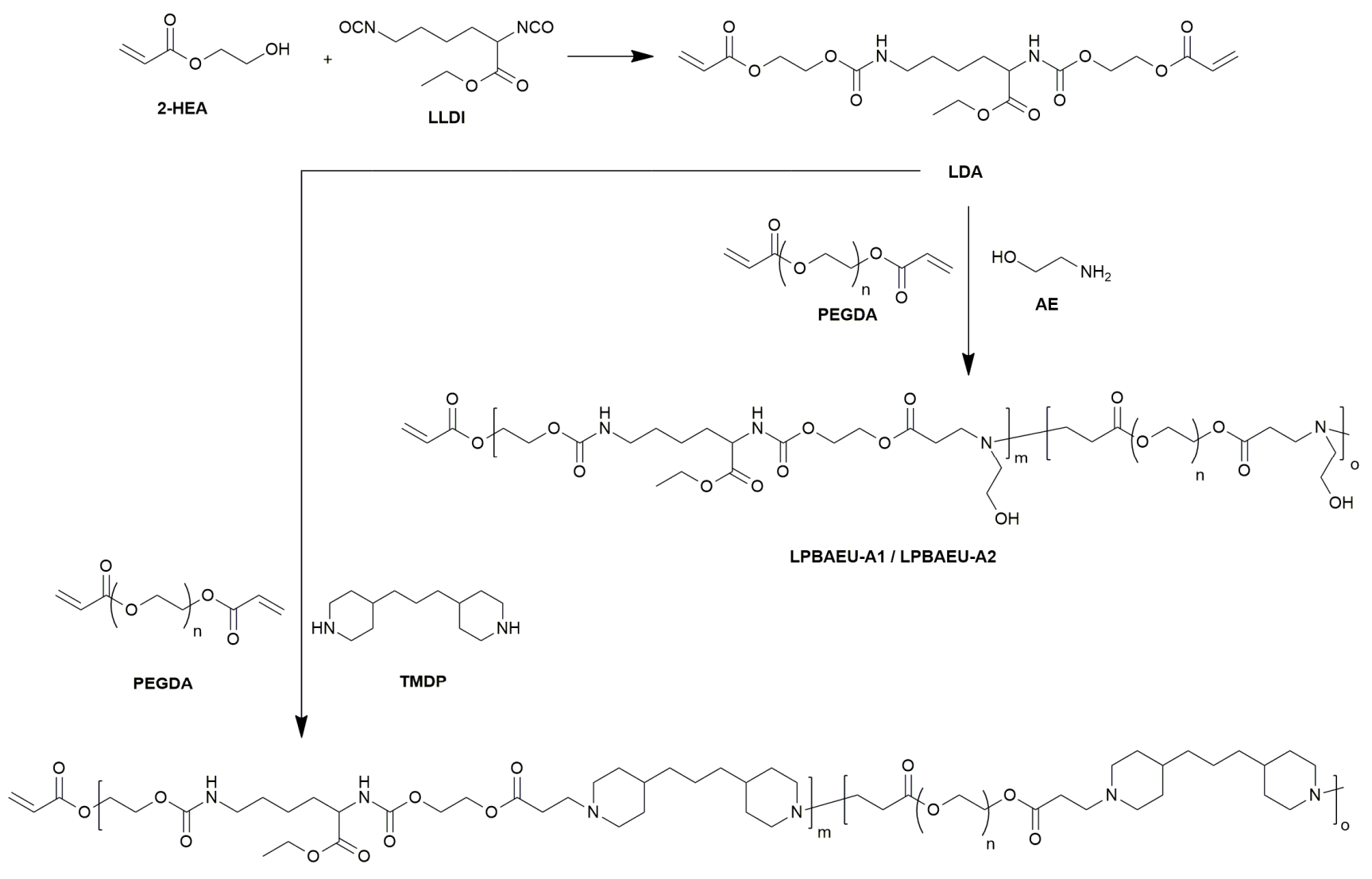

LPBAEU-T1 / LPBAEU-T2

Scheme 1. Schematic diagram of the synthesis and chemical structures of the polymers.

the solution was removed and replaced with the same amount of fresh PBS to maintain total volume constant. Quantitative analysis of the removed PBS solution was done by measuring the UV absorbance at $346 \mathrm{~nm}$ by using a UV spectrometer (Lambda 900, Perkin Elmer) operating at a resolution of $1 \mathrm{~nm}$. To establish the relationship between the drug concentration and absorbance, the standard calibration curve of free DH in PBS at the wavelength of $346 \mathrm{~nm}$ was developed $\left(\mathrm{R}^{2}=0.9988\right)$. The quantity of $\mathrm{DH}$ released was calculated by comparing the obtained UV-Vis spectra with the standard calibration curve of free $\mathrm{DH}$. All experiments were repeated 3 times. To determine the entrapped drug content in the network film samples, the drug release studies were continued until the samples became brittle. The entrapped DH amount was measured by the same method as described above. The drug loading percentage, LC, was calculated on the basis of the following formula 40

$$
L C(\%)=w_{D} / w_{N F} \times 100
$$

where $w_{D}$ and $w_{N F}$ represent the weights of loaded drug and network film, respectively.

\section{Results and discussion}

Structural characterization of LPBAEU macromers and networks
Biodegradable LPBAEU macromers were synthesized by reacting two different diacrylate and amine compounds having different hydrophilic/hydrophobic characteristics as shown in Scheme 1. Briefly, the urethane linkage (-NH-COO-) containing LDA monomer was obtained by the reaction of isocyanate group (LLDI) and hydroxyl group (HEA). Then, LPBAEU macromers were obtained by conjugate addition of the diacrylate to amine for 72 hours at $55{ }^{\circ} \mathrm{C}$, with conversions on the order of $88-91 \%$ (Table 1 ). As a second step, the terminal acrylate groups of these macromers were crosslinked by using APS and TEMED. The ratio of LDA to PEGDA was kept constant at $1: 1$ in all polymerizations and the total diacrylate to amine molar ratios (D:A ratio) were adjusted to be 1.2:1 and 1.4:1, respectively. Table 1 summarizes the characteristics of the LPBAEUs synthesized at different D:A ratios. Their molecular structure was confirmed using ATR-FTIR and ${ }^{1} \mathrm{H}-\mathrm{NMR}$ techniques as discussed below.

From the FTIR spectrum of LDA (Fig. $1 A(b)$ ), the absence of characteristic peak of isocyanate group at $2238 \mathrm{~cm}^{-1}$ and the existence of new stretching and bending vibrations of $\mathrm{N}-\mathrm{H}$ peak at $3321 \mathrm{~cm}^{-1}$ and $1535 \mathrm{~cm}^{-1}$ indicated the complete reaction of hydroxyl and isocyanate groups and proved the successful synthesis of LDA compound. ${ }^{41}$ The absorption bands at around $2800-3000 \mathrm{~cm}$ 1 are related to the symmetric stretching vibration of the $\mathrm{C}-\mathrm{H}$ groups. The peak at at $3324 \mathrm{~cm}^{-1}$ and the broad absorption band at 

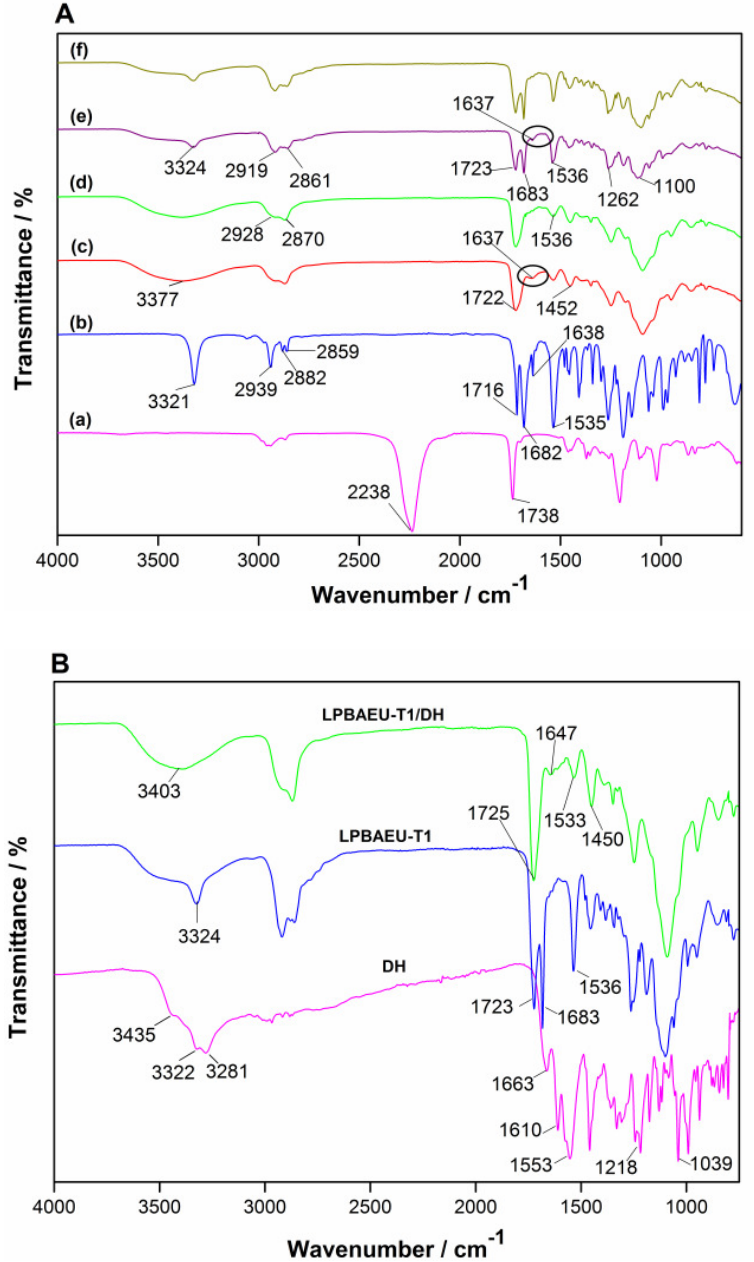

Fig. 1 (A) ATR-FTIR spectra of (a) LLDI, (b) LDA, (c) LPBAEU-A1 macromer, (d) LPBAEU-A1 network, (e) LPBAEU-T1 macromer, ( $f$ ) LPBAEU-T1 network; and (B) ATR-FTIR spectra of DH and DHloaded LPBAEU-T1 network.

$3377 \mathrm{~cm}^{-1}$ are due to the stretching vibration of $\mathrm{N}-\mathrm{H}$ groups of LPBAEU-T1 and the overlapped stretching vibrations of $\mathrm{N}-\mathrm{H}$ and $\mathrm{O}-$ $\mathrm{H}$ groups of LPBAEU-A1, respectively. Since all the $\mathrm{NH}_{2}$ groups of amine monomers were consumed through the conjugate addition reaction, the observed $\mathrm{N}-\mathrm{H}$ stretching in the spectra was only due to the urethane structure. ${ }^{42}$ In the carbonyl region of LDA, the obtained peaks at $1716 \mathrm{~cm}^{-1}$ and $1682 \mathrm{~cm}^{-1}$ are due to the stretching vibrations of the free carbonyl $(\mathrm{C}=\mathrm{O})$ of ester and urethane groups. ${ }^{43}$ In the FTIR spectrum of LPBAEU-T1 network (Fig. $1 A(f)$ ) these ester and urethane peaks can be seen very clearly while in the spectrum of LPBAEU-A1 (Fig. 1A(d)), these stretching bands overlapped due to hydrogen bonded carbonyl groups and only one absorption band appears at $1722 \mathrm{~cm}^{-1}$ for the carbonyl groups. ${ }^{43}$ Also, the absorbances at $1536 \mathrm{~cm}^{-1}$ and $1262 \mathrm{~cm}^{-1}$ are originated from $\mathrm{N}-\mathrm{H}$ bending and $\mathrm{C}-\mathrm{N}$ stretching vibrations. From the FTIR spectra of LPBAEU-A1 and LPBAEU-T1 macromers, as shown in Fig. $1 \mathrm{~A}(\mathrm{c}, \mathrm{e})$, the observed absorption peak at $1637 \mathrm{~cm}^{-1}$ corresponding to the stretching vibration of terminal acrylate groups $(C=C)$ demonstrated that macromers having acrylate end groups were formed via Michael type addition reaction because of the diacrylate to amine molar ratio exceeding $1 .{ }^{44}$

Fig. 1B compares the FTIR spectra of DH and DH-loaded LPBAEU-T1 network film. Doxycycline hyclate exhibited the following characteristic peaks ${ }^{45}$ at around $3500-3200 \mathrm{~cm}^{-1}, 1663 \mathrm{~cm}^{-}$ $1,1610 \mathrm{~cm}^{-1}$ and $1553 \mathrm{~cm}^{-1}$ which were assigned to $\mathrm{O}-\mathrm{H}$ and primary amine $\mathrm{N}-\mathrm{H}$ stretching vibrations, $\mathrm{C}=\mathrm{O}$ stretching vibration and $\mathrm{N}-\mathrm{H}$ bending and $\mathrm{C}-\mathrm{N}$ stretching vibrations of $\mathrm{CONH}_{2}$ group, respectively. After $\mathrm{DH}$ loading, the peak of $3324 \mathrm{~cm}^{-1}$ became wider and flatter, and the region between 3200 and $3600 \mathrm{~cm}^{-}$ 1 represented the overlapping peaks of stretching vibration of $\mathrm{O}-\mathrm{H}$ and $\mathrm{N}-\mathrm{H}$ and the enhancement of hydrogen bonding. Also, $\mathrm{N}-\mathrm{H}$ bending shifted from 1536 to $1533 \mathrm{~cm}^{-1}$, and in carbonyl region, one strong absorption band at $1725 \mathrm{~cm}^{-1}$ and a new band at around $1647 \mathrm{~cm}^{-1}$ were obtained, corresponding to combined carbonyl stretching of urethane and ester groups. ${ }^{43}$ These findings suggest the formation of possible hydrogen bonding interactions between the drug and the network through their polar amino, hydroxyl and amide functional groups, as shown in Fig. S1 in Supporting Information.

The samples were analyzed with ${ }^{1} \mathrm{H}-\mathrm{NMR}$ to further confirm the structure and the chemical shifts of characterized protons. The reaction of LLDI and HEA in a ratio of 1:2 resulted in the formation of LDA monomer, as demonstrated by the distinctive peaks in the ${ }^{1} \mathrm{H}$-NMR spectrum (Fig. 2a). The peaks of HEA related methylene protons were detected at $4.34 \mathrm{ppm}$ (labeled " $\mathrm{b}$ ") while the chemical shifts of methyl and methylene protons in the ethyl ester moiety of LLDI were assigned at $1.36 \mathrm{ppm}$ (labeled "e") and $4.81 \mathrm{ppm}$ (labeled "d"), respectively. ${ }^{42}$ The aliphatic methylene protons resulting from L-lysine were depicted at $1.52 \mathrm{ppm}, 1.50 \mathrm{ppm}$ and $3.18 \mathrm{ppm}$ (labeled "f", "g+h" and "j", respectively) ${ }^{33}$ and the peak at $3.76 \mathrm{ppm}$ (labeled " $\mathrm{c}$ ") related to $-\mathrm{CH}$ proton of L-lysine. Characteristic peaks of acrylate end group protons were assigned at $5.85 \mathrm{ppm}, 6.19 \mathrm{ppm}$ and 6.46 ppm (labeled "a2", "a3" and "a1"). ${ }^{34}$

The spectra in Fig. $2 b$ and $2 c$ indicated the chemical diversity of the LPBAEU-A1 and LPBAEU-T1 macromers. Each ${ }^{1} \mathrm{H}-\mathrm{NMR}$ spectrum with labeled protons exhibited the characteristic signals of LDA monomer, PEG, amines (AE and TMDP) and also terminal acrylate groups. As shown, the distinctive peaks related with the structure of LDA were seen in both of the spectra. In the ${ }^{1} \mathrm{H}-\mathrm{NMR}$ spectrum of LPBAEU-A1 (Fig. 2b), the methylene proton signals attached to hydroxyl group were clearly visible at 2.51 and $3.18 \mathrm{ppm}$ (labeled " $\mathrm{m}$ " and " $\mathrm{n}$ ") while peaks from $2.61 \mathrm{ppm}$ and $2.83 \mathrm{ppm}$ (labeled " $\mathrm{k}$ " and "I") were related to the methylene protons in the polymeric chain. ${ }^{46}$ The remaining signal near 3.69 ppm (labeled "o") was linked to the methylene protons of PEG. ${ }^{47}$

In the spectrum of LPBAEU-T1 (Fig. 2c) there were three new signals due to the methyl and methylene protons of TMDP ring at $1.68 \mathrm{ppm}$ and $2.55 \mathrm{ppm}$ (labeled "o", which overlaps with peak " $\mathrm{f}$ " and " $\mathrm{m}$ ") and the aliphatic methylene protons of TMDP at $1.36 \mathrm{ppm}$ (labeled " $n$ "). ${ }^{47}$ The H-NMR results confirmed by IR spectra proved that the LDA monomer and the LPBAEU macromers with acrylate end groups were successfully synthesized. 
<smiles>C=CC(=O)OCCOC(=O)NC(C)CC(C(=O)OCOC)C(C)NC(=O)OCCOC(=O)C=C</smiles>
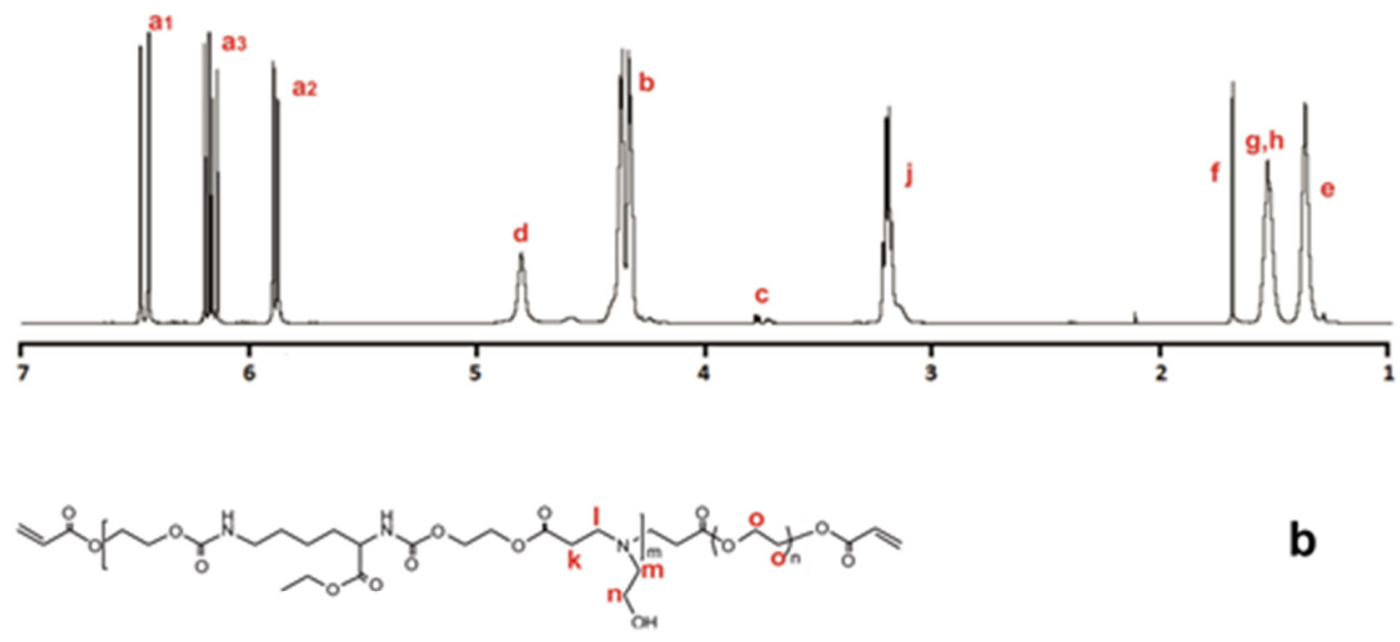

b

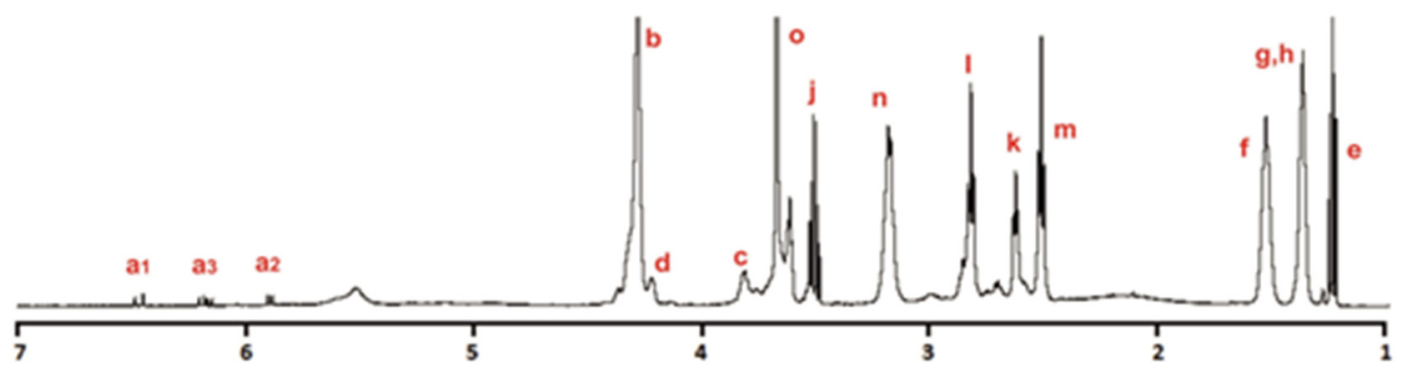

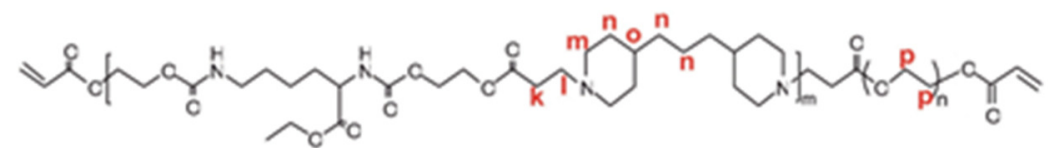

C

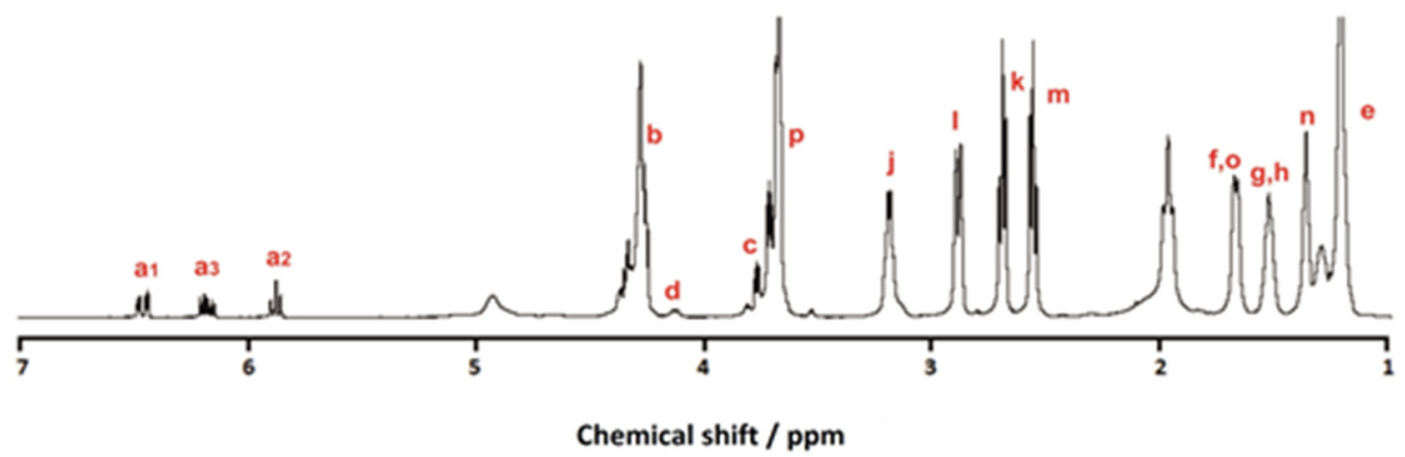

Fig. $2{ }^{1} \mathrm{H}-N M R$ spectra of (a) LDA, (b) LPBAEU-A1 and (c) LPBAEU-T1 macromers.

From the GPC results, the weight average molecular weights of the macromers $\left(\overline{\boldsymbol{M}}_{\boldsymbol{w}}\right)$ were found to be between $6180 \mathrm{~g} \mathrm{~mol}^{-1}$ and $8350 \mathrm{~g} \mathrm{~mol}^{-1}$ relative to polystyrene standards in chloroform (Table 1). Previous studies have showed that step-growth polymerization between diacrylate and amine monomers controls the molecular weight of the obtained macromer, and the maximum molecular weight is obtained when D:A ratio is 1:1 and the molecular weight decreases as the molar ratio increases. ${ }^{1,11}$ As expected, $\bar{M}_{w}$ of the resulting $L P B A E U$ macromers decreased with increasing 
molar ratio from $1.2: 1$ to $1.4: 1$. This polymerization also determines the amount of diacrylate end groups that are responsible for network formation through the subsequent free radical polymerization. ${ }^{1}$ Sol fraction is directly related with the double bond conversion of the system and indicates the crosslinking efficiency of the system. ${ }^{1}$ In biomedical applications, the sol fraction value of the system is crucial because the released parts can be toxic for the surrounding tissue and also high sol fraction values can adversely affect the final material properties, so the soluble parts must be removed before the application. ${ }^{48}$ The soluble parts in the network structure are likely due to the unreacted macromers with acrylate end groups which are released when the network is swollen in DCM. The sol fraction values showed that the networks with high D:A ratios (low $\bar{M}_{w}$ ) had lower sol fraction values $(\leq 6.4 \%$, Table 1$)$. This can be explained by the tendency of lower molecular weight macromers to react faster than the higher molecular weight macromers. Also, the amount of double bonds is greater for higher ratios and this allows lower molecular weight macromers to reach higher double bond conversions and increases crosslinking density. ${ }^{1}$

Surface wettability of a biomaterial is of importance to determine the material behaviour in a biological medium, such as surface interaction of polymeric material with cells in the human body. ${ }^{49}$ Therefore, the wettability of the crosslinked networks was identified through water contact angle measurements. The obtained contact angle values of the network films were between $29.8^{\circ}$ and $69.3^{\circ}$ as given in Table 1 , indicating the hydrophilic nature of the networks. It can be observed that the contact angles of LPBAEU-A1/A2 networks are much lower than that of LPBAEU-T1/T2 networks due to the highly hydrophilic characteristic of $A E$ monomer. As $D: A$ ratio increased from 1.2:1 to 1.4:1, the contact angle increased in the same trend due to the increased surface hydrophobicity.

The glass transition temperatures of these crosslinked LPBAEU networks were depicted in Fig. 3. A common feature among the polymeric networks is their low $T_{g}$ values which are much lower than room temperature, ranging from $-52.6^{\circ} \mathrm{C}$ to $46.6^{\circ} \mathrm{C}$. No crystallization or melting peaks were observed for all the samples despite using PEG segments, implying the amorphous nature of the networks. The low molecular weight of PEG segments $\left(700 \mathrm{~g} \mathrm{~mol}^{-1}\right)$ did not promote crystallization thus resulting in undetectable crystallization peaks (Fig. 3). ${ }^{37}$ As can be seen from the results, LPBAEU-T2 and LPBAEU-A2 networks ( $D: A$ ratio of 1.4:1) showed the highest $T_{g}$ values because of the reduction in chain mobility of these highly crosslinked structures. ${ }^{50-52}$

\section{Swelling studies}

The effect of the D:A ratio and the type of the amine molecule on the swelling profile of LPBAEU networks was investigated in PBSs of $\mathrm{pH} 5.6$ and 7.4. As seen in Fig. 4A,B, all networks had similar swelling isotherms; swelling ratio gradually increased with time and then reached an equilibrium state in

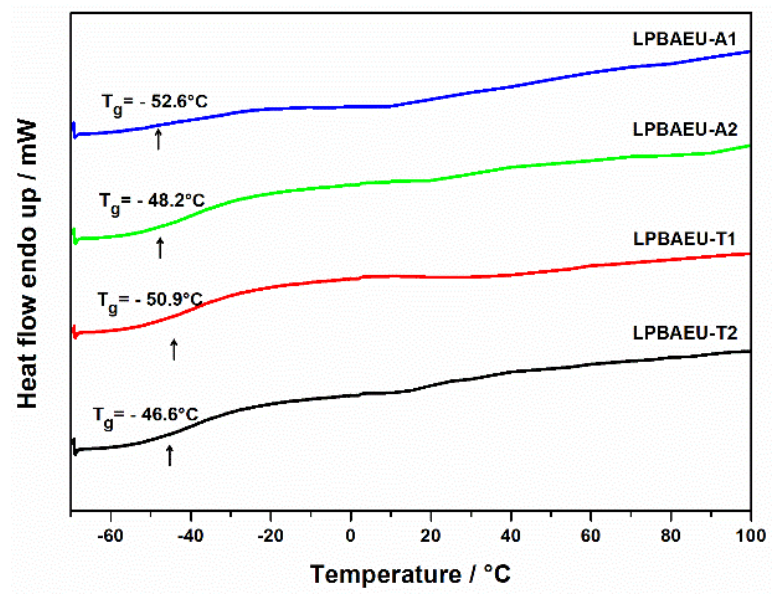

Fig. 3 DSC thermograms of LPBAEU networks. The curves were shifted vertically for clarity.

approximately $6 \mathrm{~h}$ for LPBAEU-T2 system and in $3 \mathrm{~h}$ for the other systems. It is also apparent that all networks exhibited a $\mathrm{pH}$-responsive swelling, and the equilibrium ratio of swelling in $\mathrm{pH} 5.6$ was higher than that of neutral medium (Fig. 4A,B). The main reason for this is the tertiary amine groups of $P B A E$ polymers with a pKb value between 5 and $7.2 .{ }^{8}$ The network structure becomes hydrophilic below their pKb due to the formation of positively charged amine, which allows the formation of $\mathrm{H}$-bonding with water (swollen polymer network), but more hydrophobic at the neutral pH because of the deprotonation of amino groups (compact network structure). ${ }^{8}$ Consequently, all LPBAEU networks showed higher swelling degrees, almost twice, in $\mathrm{pH} 5.6$ in comparison to neutral environment, depending on their structure and $D: A$ ratio.

The interaction between water and LPBAEU networks was mainly determined by the chemical structure of the network, and hydrophilic polymers are more prone to form hydrogen bonds with water molecules and tend to swell to a greater extent. ${ }^{53}$ From a structural point of view, since $A E$ monomer is more hydrophilic than TMDP, high penetration of water leads to the high swelling ratios up to $252.2 \%(\mathrm{pH} 5.6)$ for LPBAEUA1 polymer. Conversely, $166 \%$ ( $\mathrm{pH} 5.6$ ) swelling was observed for LPBAEU-T1 due to the reduction in water uptake of this hydrophobic network. The degree of swelling was also dependent on the crosslinking density. As depicted in Fig.4A,B, maximum swelling ratios of LPBAEU-A2 and LPBAEU-T2 network films were found to be $65.6 \%$ and $32.4 \%$, respectively while LPBAEU-A1 and LPBAEU-T1 absorbed $148.7 \%$ and $93.4 \%$ water at equilibrium at $\mathrm{pH}$ 7.4. LPBAEU-A2 and LPBAEU-T2 networks that have high $D: A$ ratio were tightly crosslinked, these rigid and dense structures did not allow large quantities of water to reach the inner parts of the network and hence, the swelling capability was reduced.

Swelling kinetics. The water diffusion into the polymer network causes polymer chain relaxation and subsequently 

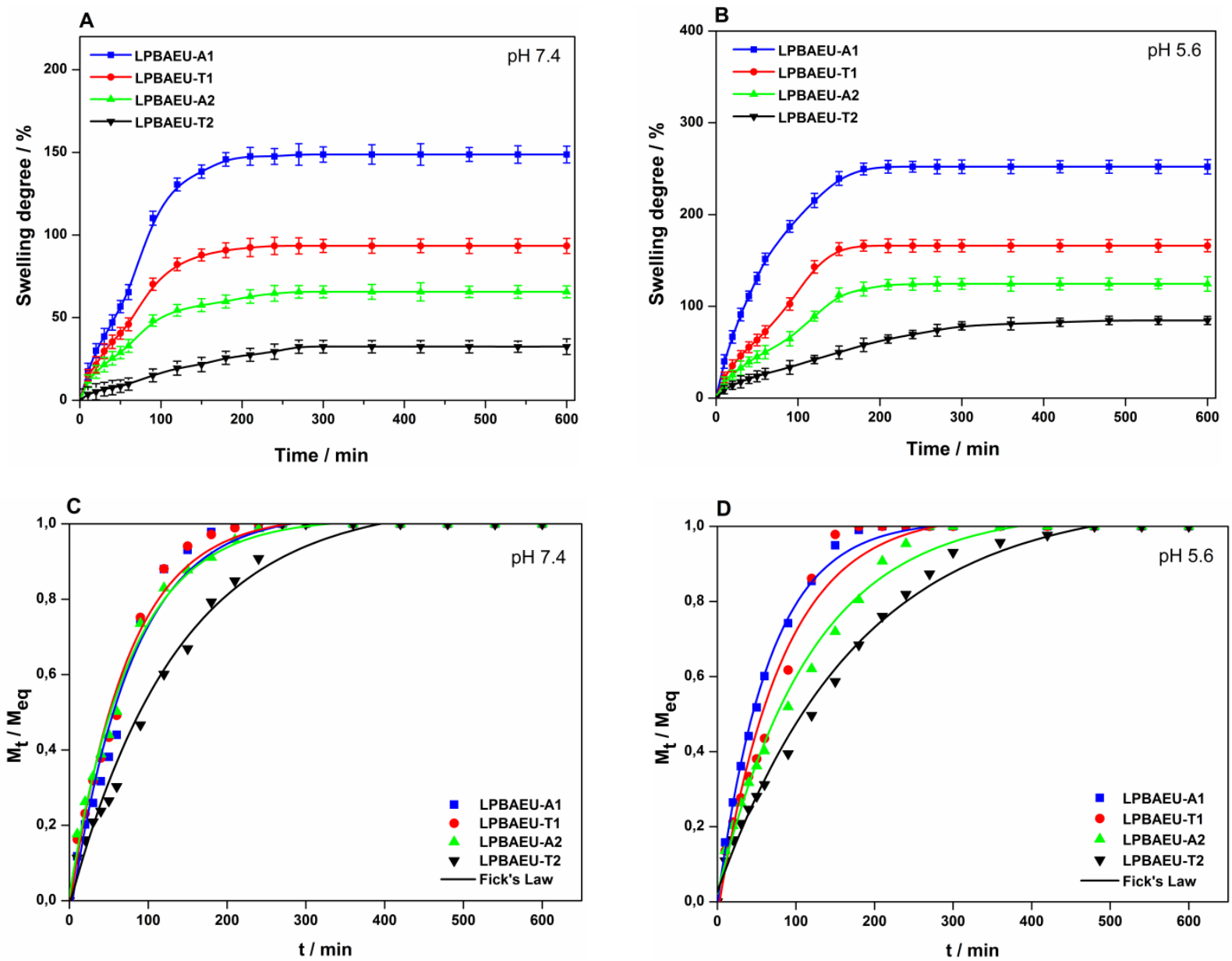

Fig. 4 Swelling properties of LPBAEU networks in (A) pH 7.4 and (B) pH 5.6 PBS solution. The data represented as mean \pm standard deviation ( $n=3$ ). The plot of $\mathrm{M}_{t} / \mathrm{M}_{\mathrm{eq}}$ as a function of time for LPBAEU network films in (C) pH 7.4 and (D) pH 5.6 PBS solution.

polymeric network to begin expanding in aqueous solution. ${ }^{53}$ The water diffusion mechanism through the network can be identified based on the Korsmeyer-Peppas power-law expression as shown in Equation 3.38,54

$$
\ln \left(\frac{M_{t}}{M_{e q}}\right)=\ln K+n \cdot \ln t
$$

Here, $M_{t}$ stands for the swelling degree at time $t, M_{e q}$ represents the equilibrium swelling degree, $t$ is the time in seconds, $K$ is a structural/geometric constant used to identify the swelling ability of the networks and $n$ is the diffusion exponent representing the transport mechanism. This equation can be used for both Fickian and non-Fickian transport mechanisms for thin polymer films and is only valid for the initial swelling stages till $60 \%$ of the solvent uptake $\left(\mathrm{M}_{\mathrm{t}} / \mathrm{M}_{\mathrm{eq}} \leq 0.6\right) .{ }^{54}$ The diffusion exponent, $n$ determines the type of transport mechanism, i) $n=0.5$ for Fickian diffusion, ii) $0.5<n<1.0$ for non-Fickian diffusion, iii) $n \geq 1.0$ for the relaxation controlled diffusion and iv) $n<0.5$ for less-Fickian diffusion. ${ }^{38}$
The plots of $M_{t} / M_{e q}$ versus $t$ were drawn (Fig. 4C,D) and the obtained diffusion parameters, $K$ and $n$, were summarized in Table S1+. It is observed that the $n$ values are between 0.725 and 0.535 for $\mathrm{pH} 7.4$ and, 0.741 and 0.588 for $\mathrm{pH}$ 5.6, both higher than 0.5 , indicating non-Fickian behaviour of the networks in both solutions. Thus, the penetration rate and polymer relaxation rate control the overall water uptake. The obtained determination coefficient, $\mathrm{R}^{2}$, values are above 0.99 , indicating the excellent model fitting. It is also apparent from Table S1+ that the $n$ values decreased constantly with decreasing hydrophilic characteristic of the network in both cases, $\mathrm{pH} 5.6$ and 7.4, and that $\mathrm{n}$ values are higher for low $\mathrm{pH}$ value.

Voigt model ${ }^{37}$ was further used to determine the rate of water diffusion into the LPBAEU networks at $\mathrm{pH} 5.6$ and 7.4 as given in Equation 4.

$$
S_{t}=S_{e}\left(1-e^{-t / \tau}\right)
$$

where $S_{t}$ and $S_{e}$ are the swelling rate at time $t$ and the equilibrium swelling rate, respectively. $\tau(\mathrm{min})$ is the rate 
parameter that is a measure of the swelling rate and low $\tau$ values indicates higher swelling rates. It is apparent that, the diffusion rate, $\tau$, values are lower at neutral medium compared to $\mathrm{pH} 5.6$ medium (Table S1+). Among the networks, LPBAEU$\mathrm{T} 2$ has the lowest swelling rate and the highest $\tau$ value because of its highest D:A ratio.

\section{Mechanical properties}

LPBAEU networks need to possess sufficient mechanical strength to be used in local drug delivery applications. Therefore, the ultimate tensile strength, Young's modulus and elongation at break of LPBAEU crosslinked network films were determined and the results are given in Table 2 . It can be seen that the ultimate tensile strength and Young's modulus of the networks increased whereas the elongations at break decreased significantly with increasing $D / A$ ratio from $1.2 / 1$ to 1.4/1. LPBAEU-T2 network having D/A ratio of $1.4 / 1$ possessed highest tensile strength $(1.4 \pm 0.18 \mathrm{MPa})$, which is 1.8 times higher than that of LPBAEU-A1 network with D/A ratio of $1.2 / 1$. The increase in $D / A$ ratio led to an increase in the crosslinking density of the network films. This generally decreases the ductility (elongation at break) of the films and the networks became more rigid and brittle in nature. On the

Table 2 Mechanical properties of LPBAEU networks.

\begin{tabular}{cccc}
\hline Sample & $\begin{array}{c}\text { Tensile Strength } \\
\text { / MPa }\end{array}$ & $\begin{array}{c}\text { Elongation } \\
\text { At Break } \\
/ \%\end{array}$ & $\begin{array}{c}\text { Young's } \\
\text { Modulus } \\
\text { / MPa }\end{array}$ \\
\hline LPBAEU-A1 & $0.5 \pm 0.19$ & $40.7 \pm 1.19$ & $1.2 \pm 0.61$ \\
LPBAEU-A2 & $1.1 \pm 0.15$ & $19.2 \pm 0.12$ & $5.7 \pm 0.46$ \\
LPBAEU-T1 & $0.7 \pm 0.04$ & $32.9 \pm 0.21$ & $2.1 \pm 0.57$ \\
LPBAEU-T2 & $1.4 \pm 0.18$ & $12.0 \pm 0.49$ & $9.7 \pm 0.38$ \\
\hline
\end{tabular}

other hand, at the same D/A ratio (1.2/1 or $1.4 / 1)$, lower tensile strength and Young's modulus values were obtained for LPBAEU-A1 and LPBAEU-A2 compared to their counterparts, LPBAEU-T1 and LPBAEU-T2. This can be explained with the differences in their structure, as LPBAEU-A1 or LPBAEU-A2 has more flexible structure due to its composition.

These properties are comparable to $\mathrm{pH}$-sensitive poly(vinyl alcohol) and poly(g-glutamic acid) hydrogel drug delivery systems and crosslinked PEO hydrogel films reported in the literature. ${ }^{55,56}$

\section{Hydrolytic and Enzymatic Degradation}

The polymeric carrier must undergo controlled degradation to yield water soluble non-cytotoxic breakdown products that subsequently are excreted from the body after completing their biological functions (i.e. releasing the drug). ${ }^{57}$ Previous studies have demonstrated that PBAE based polymers are prone to degradation due to highly hydrolytic susceptibility of the ester linkages, and the polymeric chains are cleaved into fragments to form lower molecular weight degradation byproducts, like bis(beta-amino acid)s. ${ }^{11,48}$ The stability of the urethane bond under physiological conditions is controversial; some studies have shown the hydrolysis of lysine-derived polymers to yield lysine, ${ }^{22,23}$ while others have reported that the degradation of urethane linkages can only be achieved by enzyme. ${ }^{58,59}$

To investigate the effect of hydrophilic/hydrophobic characteristic of amine monomer and the $D: A$ ratio on the physiological stability of chemically crosslinked LPBAEU network films, in vitro degradation studies were performed in the presence and absence of lipase. The weight losses of the LPBAEU polymers during degradation in PBS are shown in Fig. $5 A, B$. Comparing these two graphs, it can be seen that the degradation rates of all the network films increased in case of enzymatic degradation verifying that the hydrolysis of ester and urethane bonds can be enhanced with the addition of lipase from porcine pancreas that has reported previously to have effect on ester and urethane degradation. ${ }^{60}$

Among the samples, LPBAEU-T2 network has the lowest degradation rate, so in 14 days, before becoming fragile, $48.7 \%$ and $65.3 \%$ mass losses were observed after hydrolytic and enzymatic degradation, respectively. The tight network structure of LPBAEU-T2 (D:A ratio of 1.4:1) has protected the ester bonds by reducing the water penetration, and thus led to the slow degradation. However, LPBAEU-A1 and LPBAEU-T1
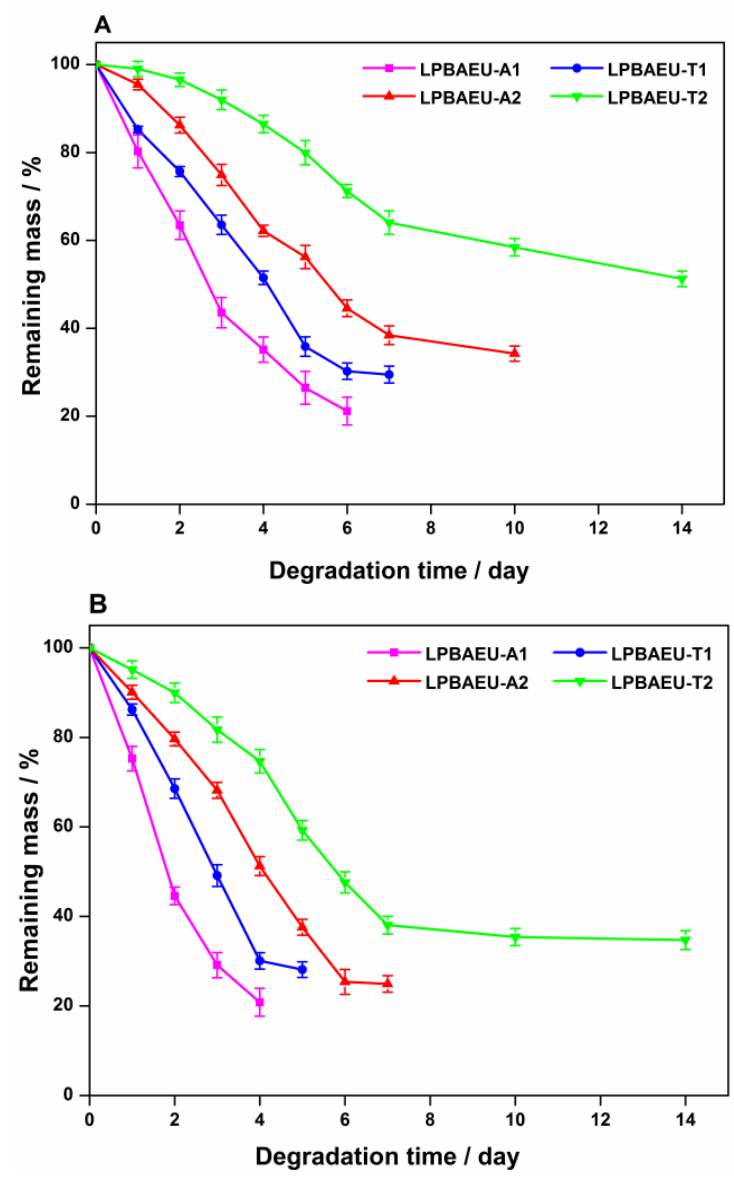

Fig. 5 In vitro degradation profile of LPBAEU network films in PBS solution during (A) hydrolytic and (B) enzymatic degradation at $37^{\circ} \mathrm{C}$. The data represented as mean \pm standard deviation $(n=3)$. 
networks that have a molar ratio of 1.2:1 degraded much faster; the network films became thin, fragile and nearly $78.8 \%$ and $70.5 \%$ of weight losses were obtained in PBS without lipase within 6 or 7 days, respectively and almost the same weight loss within 4 or 5 days in case of enzymatic degradation (Fig. 5). This is to be expected because lightly crosslinked networks allow the penetration of large quantities of water and thus, accelerate the degradation. In summary, all LPBAEU networks degraded easily because of their amorphous structure and lower glass transition temperature which facilitate the diffusion of water into the structure and makes them more susceptible to degradation. ${ }^{52}$ Additionally, the networks with quick degradation are consistent with the networks with high swelling degrees.

To analyze the degradation profile of the LPBAEU networks, FTIR studies were carried out, and the FTIR spectra of the LPBAEUT1 network during degradation were given in Fig. 6A. Degradation of the network has resulted in changes which can be traced by differences in three regions of the FTIR spectra. In region I, the broad absorption band at $3324 \mathrm{~cm}^{-1}$, corresponding to the stretching vibration of $\mathrm{N}-\mathrm{H}$ group shifted to the left side of the spectrum after 5 days and its intensity was decreased, while this band was replaced by a broad signal at $3600 \mathrm{~cm}^{-1}$ referring two characteristic groups, $\mathrm{O}-\mathrm{H}$ and $\mathrm{N}-\mathrm{H}$, on day 7 (Fig. S2A ${ }^{\dagger}$ ). In region II, the peak at $1723 \mathrm{~cm}^{-1}$ characterizes $\mathrm{C}=\mathrm{O}$ stretching vibrations in ester structure, while the peak at $1683 \mathrm{~cm}^{-1}$ corresponds to $\mathrm{N}-\mathrm{C}=\mathrm{O}$ stretching vibration in the urethane group (Fig. $\mathrm{S}^{\mathrm{B}} \mathrm{B}^{+}$). No visible change was observed after 3 days of degradation, while, after 5 days, the bond at $1683 \mathrm{~cm}^{-1}$ disappeared and a new broad peak was formed at $1722 \mathrm{~cm}^{-1}$, indicating the disintegration of urethane bond into carboxylic acid-terminated lysine structure as a result of hydrolysis. In region III, the absorbances at $1536 \mathrm{~cm}^{-1}$ and $1264 \mathrm{~cm}^{-1}$ could be attributed to $\mathrm{N}-\mathrm{H}$ bending and $\mathrm{C}-\mathrm{N}$ stretching vibration in the -C-NH group. On the fifth day of study, the sharp peak at 1536 $\mathrm{cm}^{-1}$ appeared as a wide, broad peak, indicating the decreased intensity of $\mathrm{N}-\mathrm{H}$ bond. After 7 days, this peak shifted to $1546 \mathrm{~cm}^{-1}$ and became broader by overlapping with other peaks. Also, the decrease in the intensity of $\mathrm{C}-\mathrm{N}$ peak and shifting of the peak to
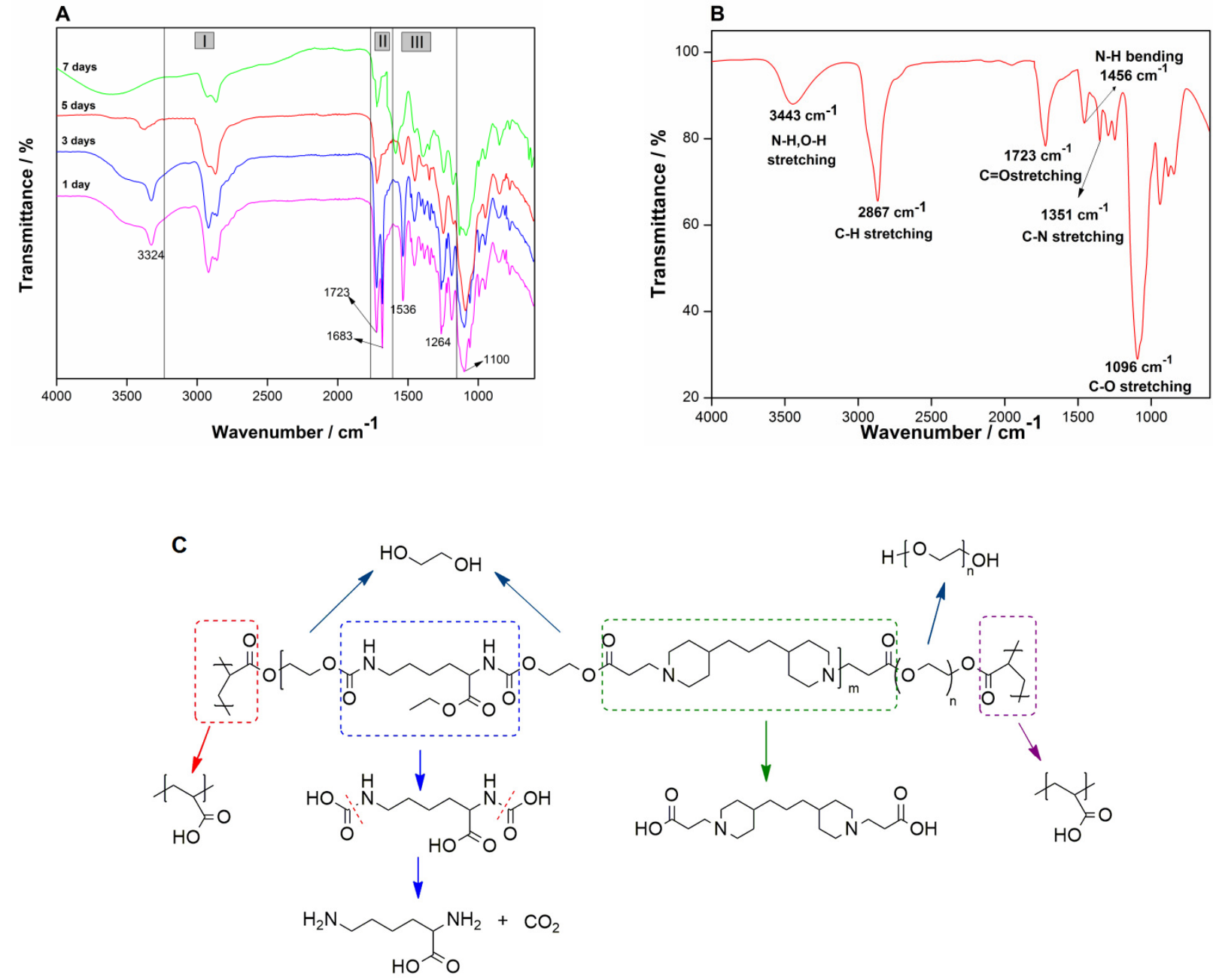

Fig. 6 ATR-FTIR spectra of (A) LPBAEU-T1 network during degradation, (B) degradation products of LPBAEU-T1 network after 7 days degradation, and (C) Potential degradation products of crosslinked LPBAEU-T1 network. 

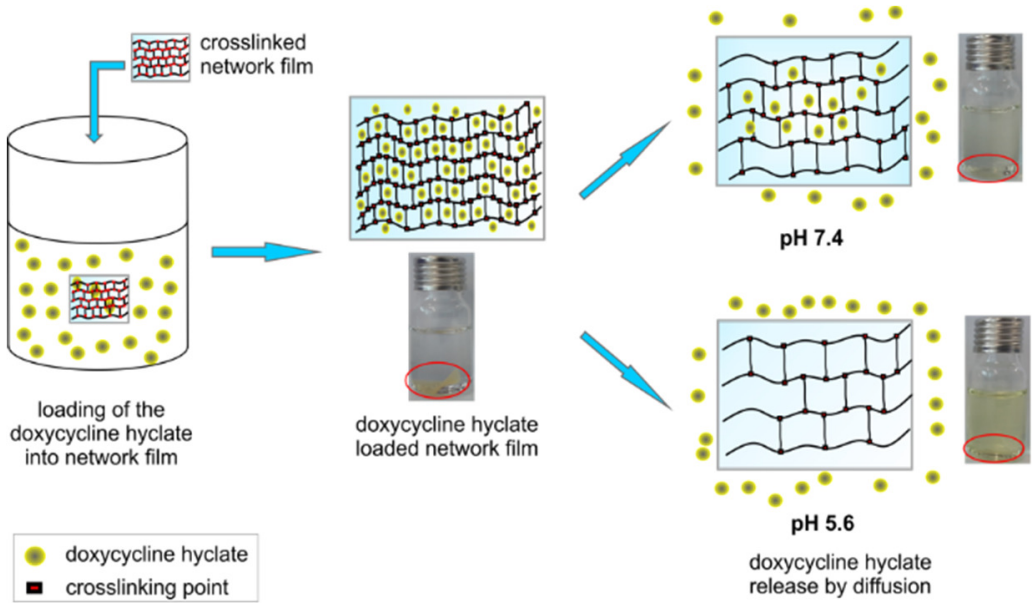

doxycycline hyclate release by diffusion

Fig. 7 Schematic diagram illustrating the loading of doxycycline hyclate into the network films and in vitro release in acidic $\mathrm{pH}$ (pH 5.6) and physiological $\mathrm{pH}(\mathrm{pH}$ 7.4). The pictures show the doxycycline hyclate loaded LPBAEU-A1 film after loading and maintained within PBS of $\mathrm{pH} 7.4$ and at $\mathrm{pH} 5.6$ for 72 hours.

$1248 \mathrm{~cm}^{-1}$ indicated the reduction in C-N bond (Fig. S2C $\mathrm{C}$ ).

The structures of proposed degradation products of LPBAEU-T1 networks are shown in Fig. $6 \mathrm{C}$ and the FTIR spectra of these degradation products are given in Fig. $6 \mathrm{~B} .{ }^{61}$ The obtained absorption bands can be described as: the broad band at $3443 \mathrm{~cm}^{-1}$ representing $\mathrm{N}-\mathrm{H}$ and $\mathrm{O}-\mathrm{H}$ stretching; at around $2867 \mathrm{~cm}^{-1}$ representing asymmetric and symmetric $\mathrm{C}-\mathrm{H}$ stretching in hydrocarbon groups; at $1723 \mathrm{~cm}^{-1}$ representing $\mathrm{C}=\mathrm{O}$ stretching in carboxyl group; at 1456 and $1351 \mathrm{~cm}^{-1}$ representing $\mathrm{N}-\mathrm{H}$ bending and C-N stretching; and at around $1096 \mathrm{~cm}^{-1}$ representing C-O stretching vibrations. Consequently, the analysis of both FTIR spectra showed the loss of urethane structures and the formation of new degradation products such as dicarboxylic acid, poly(acrylic acid) and lysine as shown in Fig. 6C.

The degradation products of most synthetic polymers create an acidic environment that can cause inflammation at the implant site, and hence not desirable for most application areas. ${ }^{62}$ In order to examine the effect of degradation products on the $\mathrm{pH}$ of the surrounding medium, the $\mathrm{pH}$ of the degradation solutions was measured and the results were given in Fig. S3†. As can be clearly seen in these figures, the $\mathrm{pH}$ of both media changed from 7.4 to 6.9 during degradation, and thus indicated that the breakdown products do not significantly affect the $\mathrm{pH}$ value of the degradation medium.

\section{In vitro doxycycline hyclate release study}

Doxycycline hyclate was physically adsorbed on the network structure by swelling the polymeric films with drug solution (Fig. 7) and the drug loading percentages of LPBAEU-A1, LPBAEU-A2, LPBAEU-T1 and LPBAEU-T2 networks were found to be approximately $8.0 \pm 0.8 w t \%, 6.9 \pm 1.6 w t \%, 7.1 \pm 0.4 w t \%$ and $6.3 \pm 1.7 \mathrm{wt} \%$, respectively. Fig. 8 demonstrates the in vitro $\mathrm{DH}$ release profiles of the network films in two different $\mathrm{pH}$ media at $37^{\circ} \mathrm{C}$. Also, the daily doses of released $\mathrm{DH}$ on certain days of the study were given in Fig. $\mathrm{S}^{+}+$and Fig. S5t. It is obvious that the release rate of $\mathrm{DH}$ is higher in mild acidic medium with $\mathrm{pH} 5.6$ than that of neutral medium as shown schematically in Fig.7. Upon exposure to medium with $\mathrm{pH}$ 5.6, the protonation of tertiary amino groups led to repulsion of PBAE chains between two adjacent crosslinking points inside the network structure and all networks swelled to a greater extent and thus increased the drug diffusion from the network. ${ }^{63,64}$ Higher swelling ratios at $\mathrm{pH} 5.6$ created more surface for drug to diffuse from the network to the medium.

All networks showed an initial burst release that could be caused by the washing out of physically entrapped $\mathrm{DH}$ molecules that were on or close to the sample surface ${ }^{65}\left(50 \mathrm{mg} \mathrm{ml}^{-1}\right.$ water solubility $\left.{ }^{66}\right)$. This effect was seen very clearly in hydrophilic LPBAEUA1 (initial release of $451 \mathrm{\mu g} \mathrm{ml}^{-1}$ ) network which caused the highest water uptake and all drug content was released in medium of $\mathrm{pH}$ 5.6 within the first 6 hours (Fig. 8B). This network with high initial $\mathrm{DH}$ concentrations might be useful to prevent rapid bacterial growth in short time. ${ }^{26}$ The weakest burst effect was observed for LPBAEU-T2 network and only $5.4 \%$ of loaded $\mathrm{DH}\left(74 \mu \mathrm{g} \mathrm{ml}^{-1}\right)$ was released in the initial stage as a burst. It is worth noting that this lower $\mathrm{DH}$ amount is still above the minimum inhibitory concentration (MIC, $6 \mu \mathrm{g} \mathrm{ml}^{-1}$ for doxycycline) for most pathogenic bacteria. ${ }^{66}$ The daily doses of $\mathrm{DH}$ gradually decreased and then it continued to release $\mathrm{DH}$ in a more sustained manner ( $36.6 \pm 3.4 \%$ release after $72 \mathrm{~h}, \mathrm{pH}$ 5.6). Moreover, in case of the networks LPBAEU-T1 and LPBAEU-A2, which differ in the molecular structure and molar ratio, presented almost the same drug release profile and they released $88.6 \%\left(1.36 \mu \mathrm{g} \mathrm{ml}^{-1}\right)$ and $75.9 \%\left(1.23 \mu \mathrm{g} \mathrm{ml}^{-1}\right)$ of the loaded drug, respectively (after $72 \mathrm{~h}, \mathrm{pH}$ 5.6) (Fig. 8B).

Drug Release Mechanism. A single model cannot successfully explain the release behaviour of drug from a network; hence various well-known mathematical kinetic models have been used. Initially, doxycycline hyclate release kinetics from LPBAEU networks 

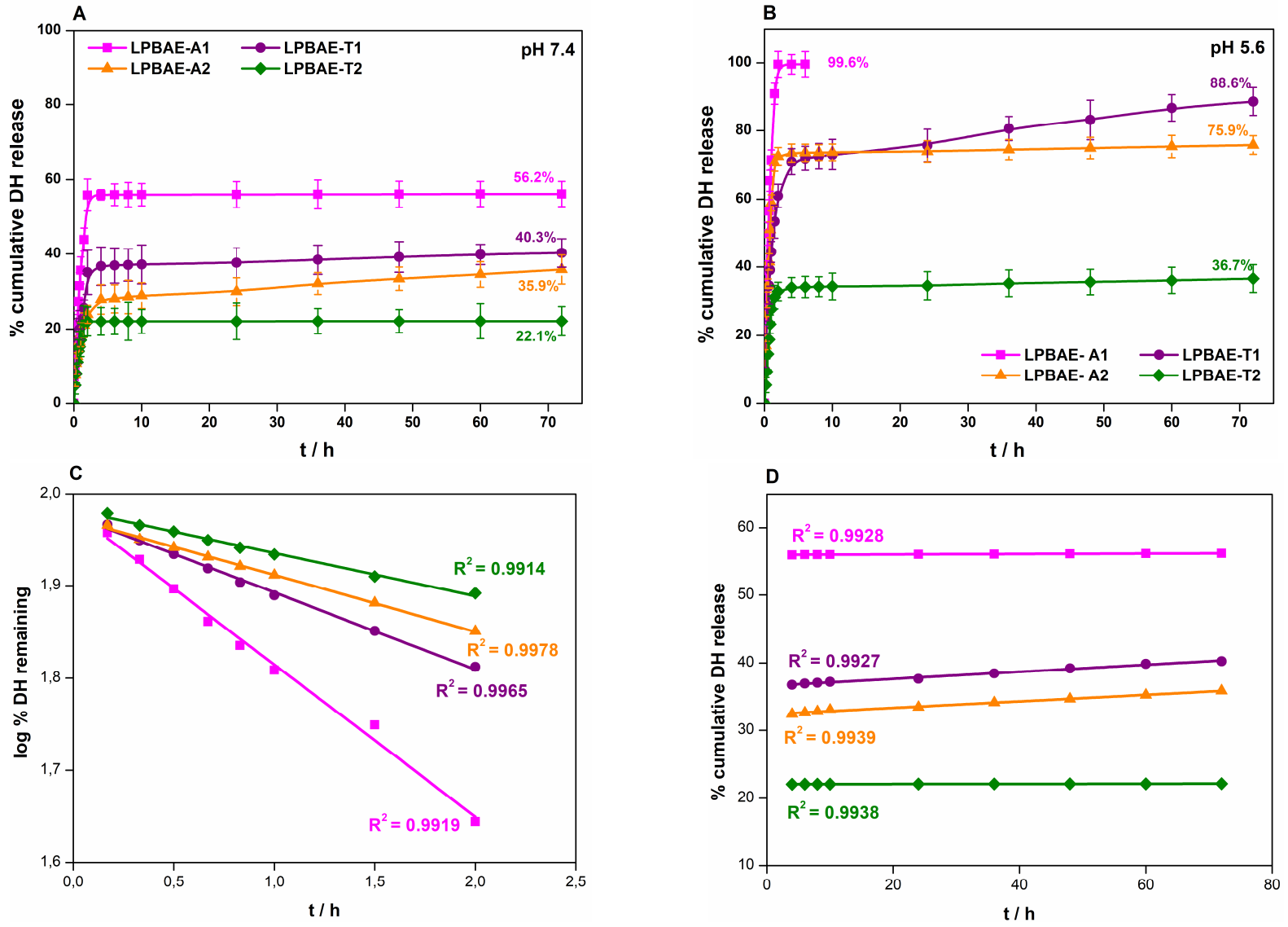

Fig. 8 In vitro release profiles of doxycycline hyclate from the networks in PBS at (A) pH 7.4 and (B) pH 5.6. (Error bars represent the mean $\pm S D(n=3)$ ). Fitting in-vitro $\mathrm{DH}$ release data to $(C)$ first-order release for early time and (D) zero-order release for late time at $\mathrm{pH}$ 7.4.

were studied by fitting into zero-order ${ }^{67}$ and first-order kinetic models ${ }^{68}$ (Supporting Information). The best release model was chosen by taking into account the correlation coefficient $\left(R^{2}\right)$ values. The models were applied separately to the early and latter $\mathrm{DH}$ release and the obtained $\mathrm{R}^{2}$ values (Fig. $8 \mathrm{C}, \mathrm{D}$ and Fig. $\mathrm{S}^{+}{ }^{+}$) showed that the early $\mathrm{DH}$ release followed the first order kinetics while the later phase fitted better to zero-order kinetics for both $\mathrm{pH}$ media.

Drug release from a polymeric network follows three main steps; first the hydration of the network, then the relaxation or erosion of the network and finally, dissolved drug transportation to dissolution medium through Fickian, non-Fickian or case II diffusion mechanism. ${ }^{69-71}$ To clarify the doxycycline hyclate release mechanism from LPBAEU networks, the release data was also analysed by using the Korsmeyer-Peppas model ${ }^{72}$ that gives main idea for drug release mechanism, the nonlinear Kopcha model ${ }^{73}$ the Higuchi model 74 and the Hixson-Crowell model ${ }^{75}$ which clarify the mechanism, defined by the following equations (Eq. 5-8).

Korsmeyer-Peppas model:

$$
\frac{M_{t}}{M}=k \cdot t^{n}
$$

Higuchi model:

$$
Q_{t}=Q_{0}+K_{H} t^{1 / 2}
$$

Hixon-Crowell model:

$$
W_{0}^{1 / 3}-W_{t^{\frac{1}{3}}}=K_{H C} t
$$

Kopcha model:

$$
Q_{t}=A t^{1 / 2}+B t
$$

where $M_{t}$ and $M$ are the quantity of released drug at time " $t$ " and the total quantity of drug loaded to the network; $Q_{t}$ and $Q_{0}$ are the quantity of drug release at time " $\mathrm{t}$ " and the initial quantity of drug in solution; $W_{0}$ and $W_{t}$ are the initial quantity of drug in polymeric matrix and the quantity of drug release at time $t$ and $Q_{t}$ is the cumulative quantity of drug release at time " $\mathrm{t}$ ". $\mathrm{k}, \mathrm{K}_{\mathrm{H}}$ and $\mathrm{K}_{\mathrm{HC}}$ are the characteristic constants of this polymer and drug system in Korsmeyer-Peppas, Higuchi and Hixson-Crowell models, respectively. Also, the diffusional exponent, ' $n$ ' value can be used to characterize the drug release mechanism of the system as explained in swelling kinetic model. ' $A$ ' and ' $B$ ' are the constants that indicates the contribution of diffusion and erosion in Kopcha model. The higher ' $A$ ' values suggest that Fickian diffusion is mainly responsible for the drug release while the higher ' $\mathrm{B}$ ' values indicate 

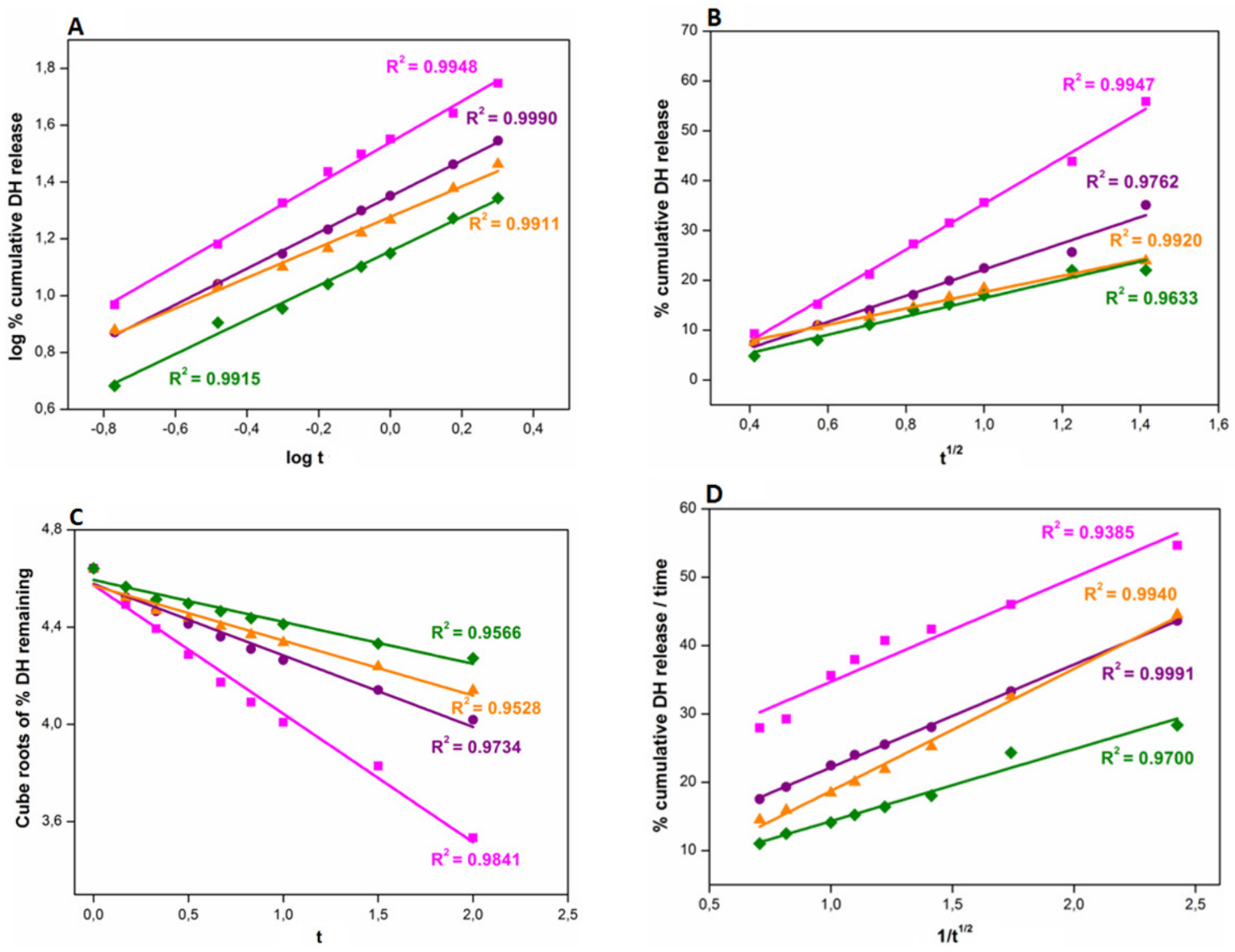

Fig. 9 Fitting the in-vitro DH release data to different mathematical models at pH 7.4. (A) Korsmeyer-Peppas model, (B) Higuchi model, (C) Hixon-Crowell model, and (D) Kopcha model. $₫$ : LPAEU-A1, •: LPAEU-T1, $\triangle$ : LPAEU-A2, ^: LPAEU-T2. The unit of time is hour.

that network erosion is dominant in drug release mechanism. ${ }^{71}$ These models fitted well to the first $60 \%$ of drug release (early time approximation). ${ }^{76}$

From the analysis of the results, the best fitting was achieved for Korsmeyer-Peppas model and the diffusion exponent $(n)$ values obtained from this model for the initial $\mathrm{DH}$ release were found to be $0.54<\mathrm{n}<0.73$ for $\mathrm{pH} 7.4$ and $0.55<\mathrm{n}<0.73$ for $\mathrm{pH} 5.6$ (Table $\mathrm{S} 2+$ ) implying non-Fickian release mechanism as proven in swelling studies. It clarifies that drug diffusion rate and polymer chain relaxation rate, i.e., erosion of the network, are comparable for these DH loaded LPBAEU network systems. ${ }^{77}$ To further confirm the $\mathrm{DH}$ release, nonlinear Kopcha model that gives detailed information about the diffusion ( $A$ exponent) and erosion ( $B$ exponent) contributions was used. The data fitting was shown in Fig. 9 and Fig S7t. The correlation coefficients of Kopcha model showed that both diffusion and erosion had contributions for this non-Fickian pattern; however, the obtained $B$ values were higher than $A$ values, i.e., the $\mathrm{A} / \mathrm{B}$ ratios were lower than 1 (Table $\mathrm{S} 2+$ ), confirming that erosion of network is mainly responsible for drug release at both $\mathrm{pH}$ values. As it can be seen from the table, with decreasing $\mathrm{pH}$ value $(\mathrm{pH} 5.6)$, the ratio of $A / B$ decreased, showing a growing contribution of the erosion effect due to a higher degree of swelling of the network structures. This effect is particularly significant for highly hydrophilic LPBAEU-A1 and LPBAEU-A2, as well as less dense LPBAEU-T1, so the drops in their $A / B$ ratio were more remarkable and hence lower $A / B$ ratios were obtained compared to that of LPBAEU-T2. In contrast, LPBAEU-T2 possessed a dense network structure which restricted the erosion effect, and hence the highest $A / B$ ratio was achieved among the four networks investigated. As shown in Fig. 9 and Fig $\mathrm{S7}+$, the lowest $\mathrm{R}^{2}$ values of LPBAEU-A1 $\left(\mathrm{R}^{2}=0.9385\right)$ for $\mathrm{pH} 7.4$ and LPBAEU-T2 $\left(R^{2}=0.9287\right)$ for $\mathrm{pH} 5.6$ implied the lowest conformity of these networks to the Kopcha model at the said $\mathrm{pH}$ condition. Also the $R^{2}$ values obtained from Hixson-Crowell and Higuchi models indicated that Higuchi model had a better fitting than Hixson-Crowell model for $\mathrm{DH}$ release.

Moreover, these observations were further supported by the diffusion coefficient (D) values of the networks that is also an important penetration parameter to characterize the systems. ${ }^{77} \mathrm{D}$ values can be determined by Equation 9, using $\mathrm{n}$ and $\mathrm{K}$ values.

$$
D^{n}=\frac{K}{4}\left(\pi l^{2}\right)^{n}
$$

where $\boldsymbol{l}$ is the thickness of the initial network films. The $D$ values of networks increased with decreasing $\mathrm{pH}$ from 7.4 to 5.6 (Table S3+). This suggests that the diffusion of $\mathrm{DH}$ molecules from networks is 
faster at lower $\mathrm{pH}$ than neutral medium. At neutral medium, the diffusion of water molecules in the network is lower, which makes the release rate slower, whereas, at $\mathrm{pH} 5.6$, the observed higher swelling rate led to increased drug release rate. It has also been noticed that the $D$ values for LPBAEU-T2 is lowest out of various networks, which is attributed to its high molar ratio and hence, it's higher degree of hydrophobicity.

\section{Conclusion}

A range of novel chemically cross-linked L-lysine based poly(beta-aminoester urethane) polymers were successfully synthesized through Michael type addition reaction followed by free radical polymerization. Their chemical and physical features were adjusted by altering the hydrophilic character of the amine and molar ratios of diacrylate to amine. The obtained equilibrium swelling ratios were essentially depended on the medium $\mathrm{pH}$, and the swelling tests revealed that these crosslinked network films had the ability to absorb water through non-Fickian diffusion model. According to the tensile data, a higher D/A ratio imparted stiffness to the network structure and the networks became more rigid. The obtained in vitro mass loss of LPBAEU network films demonstrated that the networks with high molar ratio degraded both hydrolytically and enzymatically and more slowly due to the difficulty in permeation of water through a tortuous path of the tight network. Furthermore, the network films were successfully loaded with doxycycline hyclate through swelling. The release tests demonstrated different drug release profiles for the LPBAEU networks in neutral and acidic incubation media with a reduction of released drug amount during the neutral test, showing a $\mathrm{pH}$ sensitive release functionality. Drug release mechanism was also investigated in depth using zero order, first order, Korsmeyer-Peppas, Kopcha, Higuchi and Hixson-Crowell models. The obtained results showed that drug release followed the non-Fickian type diffusion mechanism through erosion of the network. Consequently, these results confirm that the synthesized biodegradable and $\mathrm{pH}$ sensitive LPBAEU based crosslinked networks have the potential to be used in local antibiotic delivery applications.

\section{Conflicts of interest}

There are no conflicts to declare.

\section{References}

1 D. L. Safranski, M. A. Lesniewski, B. S. Caspersen, V. M Uriarte and K. Gall, Polymer, 2010, 51, 3130-3138.

2 A. M. Hawkins, T. A. Milbrandt, D. A. Puleo and J. Z. Hilt, Acta Biomater., 2011, 7, 1956-1964.

3 D. Das, P. Ghosh, A. Ghosh, C. Haldar, S. Dhara, A. B. Panda and S. Pal, Appl. Mater. Interfaces, 2015, 7, 14338-14351.

4 B. Baroli, J. Chem. Technol. Biot., 2006, 81, 491-499.
5 C. T. Huynh, S. W. Kang, Y. Li, B. S. Kim and D. S. Lee, Soft Matter, 2011, 7, 8984-8990.

6 R. Langer and N. A. Peppas, AIChE Journal, 2003, 49, 29903006.

7 M. S. Matuszowicz, J. Łukaszczyk, R. Pilawka, M. Basiaga, M. Bilewicz and D. Kusz, Int. J. Polym. Mater., 2017, 66, 1-11.

8 B. D. Ulery, L. S. Nair, and C. T. Laurencin, J. Polym. Sci. B Polym. Phys., 2011, 49, 832-864.

9 D. M. Lynn and R. Langer, J. Am. Chem. Soc., 2000, 122, 10761-10768.

10 D. Shenoy, S. Little, R. Langer and M. Amiji, Mol Pharm., 2005, 2, 357-366.

11 D. G. Anderson, C. A. Tweedie, N. Hossain, S. M. Navarro, D. M. Brey, K. J. Van Vliet, R. Langer and J. A. Burdick, Adv. Mater., 2006, 18, 2614-2618.

12 D. L. Safranski, D. Weiss, J. B. Clark, B. S. Caspersen, W. R. Taylor and K. Gall, J. Biomed. Mater. Res. A, 2011, 96, 320329.

13 A. M. Hawkins, D. A. Puleo and J. Zach Hilt, J. Appl. Polym. Sci., 2011, 122, 1420-1426.

14 F. Khan, M. Tanaka and S. R. Ahmad, J. Mater. Chem. B, 2015, 3, 8224-8249.

15 R. Langer and D. A. Tirrell, Nature, 2004, 428, 487-492.

16 A. Kiziltay, A. M. Fernandez, J. S. Roman, V. Hasirci and N. Hasirci, J. Biomater. Tissue Eng., 2012, 2, 143-153.

17 C. T. Huynh, M. K. Nguyen, J. H. Kim, S. W. Kang, B. S. Kim and D. S. Lee, Soft Matter, 2011, 7, 4974-4982.

18 Z. Y. Jian, J. K. Chang and M. D. Shau, Bioconjugate Chem., 2009, 20, 774-779.

19 G. Ciardelli, A. Rechichi, P. Cerrai, M. Tricoli, N. Barbani and P. Giusti, Macromol. Symp., 2004, 169, 261-272.

20 A. M. Fernandez, G. A. Abraham, J. L. Valentin and J. S. Roman, Polymer, 2006, 47, 785-798.

21 Z. Wang, L. Yu, M. Ding, H. Tan, J. Li and Q. Fu, Polym. Chem., 2011, 2, 601-607.

22 J.Y. Zhang, E. J. Beckman, N. P. Piesco and S. Agarwal, Biomaterials, 2000, 21, 1247-1258.

23 J. Y. Zhang, E. J. Beckman, J. Hu, G. G. Yang, S. Agarwal and J. O. Hollinger, Tissue Eng., 2002, 8, 771-785.

24 D. A. Chiappetta and A. Sosnik, Eur. J. Pharm. Biopharm., 2007, 66, 303-17.

25 C. Yang, A. B. Attia, J. P. Tan, X. Ke, S. Gao, J. L. Hedrick and Y. Y. Yang, Biomaterials, 2012, 33, 2971-2979.

26 A. K. Kasperczyk, P. Dobrzynski, M. Pastusiak, B. Jarzabek and W. Prochwicz, Int. J. Pharm., 2015, 491, 335-344.

27 A. C. S. Re, M. P. Ferreira, O. Freitas and C. P. Aires, Biofouling, 2016, 32, 1061-1066.

28 H. Hau, R. Rohanizadeh, M. Ghadiri and W. Chrzanowski, Drug Deliv. and Transl. Res., 2014, 4, 295-301.

29 S. P. Noel, H. Courtney, J. D. Bumgardner, and W. O. Haggard, Clin. Orthop. Relat. Res., 2008, 466, 1377-1382.

30 A. Bogren, R. P. Teles, G. Torresyap, A. D. Haffajee, S. S. Socransky and J. L. Wennström, J. Periodontol, 2008, 79, 827-835.

31 K. Higashi, M. Matsushita, K. Morisaki, S. Hayashi and T. Mayumi, J. Pharmacobiodyn., 1991, 14, 72-81.

32 W. L. Chiang, Y. C. Hu, H. Y. Liu, C. W. Hsiao, R. Sureshbabu, C. M. Yang, M. F. Chung, W. T. Chia and H. W. Sung, Small, 2014, 10, 4100-4105.

33 M. C. Yu, C. Y. Chang, Y. C. Chao, Y. H. Jheng, C. Yang, N. Lee, S. H. Yu, X. H. Yu, D. M. Liu and P. C. Chang, J. periodontal, 2016, 87, 742-748. 
34 Y. Tamer, H. Yıldırım, Polym. Adv. Technol., 2015, 26, 399407.

35 L. A. Moura, F. V. Ribeiro, T. B. Aiello, E. R. Duek, E. A. Sallum, F. H. N. Junior, M. Z. Casati and A. W. Sallum, J. Biomater. Sci., Polym. Ed., 2015, 26, 573-584.

36 C. T. Huynh and D. S. Lee, Colloid Polym. Sci., 2012, 290, 1077-1086.

37 V. Rana, P. Rai, A. K. Tiwari, R. S. Singh, J. F. Kennedy and C. J. Knill, Carbohydr. Polym. 2011, 83, 1031-1047.

38 N. A. Peppas and N. M. Franson, J. Polym. Sci. Polym. Phys. Ed., 1983, 21, 983-997.

39 A. M. Hawkins, N. S. Satarkar and J. Z. Hilt, Pharm. Res., 2009, 26, 667-673.

40 N. Panith, A. Assavanig, S. Lertsiri, M. Bergkvist, R. Surarit and N. Niamsiri, J. Appl. Polym. Sci., 2016, 133, DOI: 10.1002/APP.44128

41 J. Han, B. Chen, L. Ye, A. Y. Zhang, J. Zhang and Z. G. Feng, Front. Mater. Sci. China, 2009, 3, 25-32.

42 H. Fu, H. Gao, G. Wu, Y. Wang, Y. Fan and J. Ma, Soft Matter, 2011, 7, 3546-3552.

43 X. Jiang, J. Li, M. Ding, H. Tan, Q. Ling, Y. Zhong and Q. Fu, Eur. Polym. J., 2007, 43, 1838-1846.

44 O. Belaidi, T. Bouchaour and U. Maschke, Org. Chem. Int., 2013, 2013, 348379-348392.

45 F. Tamimi, J. Torres, R. Bettini, F. Ruggera, C. Rueda, M. L. Ponce and E. L. Cabarcos, J. Biomed. Mater. Res. A., 2008, 85, 707-714.

46 P. Mastorakos, E. Song, C. Zhang, S. Berry, H. W. Park, Y. E. Kim, J. S. Park, S. Lee, J. S. Suk and J. Hanes, Small, 2016, 12, 678-685.

47 J. Ko, K. Park, Y. S. Kim, M. S. Kim, J. K. Han, K. Kim, R. W. Park, I. S. Kim, H. K. Song, D. S. Lee and I. C. Kwon, J. Control. Release, 2007, 123, 109-115.

48 D. M. Brey, J. L. Ifkovits, R. I. Mozia, J. S. Katz and J. A. Burdick, Acta Biomater., 2008, 4, 207-217.

49 S. Farris, L. Introzzi, P. Biagioni, T. Holz, A. Schiraldi and L. Piergiovanni, Langmuir, 2011, 27, 7563-7574.

50 D. L. Safranski, J. C. Crabtree, Y. R. Huq and K. Gall, Polymer, 2011, 52, 4920-4927.

51 H. Fu, H. Gao, G. Wu, Y. Wang, Y. Fan and J. Ma, Soft Matter, 2011, 7, 3546-3552.

52 B. Amsden, Soft Matter, 2007, 3, 1335-1348.

53 X. Z. Zhang, D. Q. Wu and C. C. Chu, J. Polym. Sci. Polym. Phys., 2003, 41, 582-593.

54 B. Tasdelen, N. K. Apohan, O. Guven and B. M. Baysal, J. Appl. Polym. Sci., 2004, 91, 911-915.

55 Y. G. Lee, H. S. Kang, M. S. Kim and T. Son, J. Appl. Polym. Sci., 2008, 109, 3768-3775.

56 R. S. Wong, M. Ashton and K. Dodou, Pharmaceutics, 2015, 7, 305-319.

57 T. Etrych, V. Subr, R. Laga, B. R. Ihova and K. Ulbrich, Eur. J. Pharm. Sci., 2014, 58, 1-12.

$58 \mathrm{~S}$. L. Elliott, J. D. Fromstein, J. P. Santerre and K. A. Woodhouse, J. Biomater. Sci. Polym. Ed., 2002, 13, 691-711.

59 A. J. Domb, J. Kost and D. Wiseman, Handbook of Biodegradable Polymers, CRC Press, Amsterdam, 1998.

60 E. Pamuła, M. Błażewicz, C. Paluszkiewicz and P. Dobrzyński, J. Mol. Struct., 2001, 596, 69-75.

61 J. B. Wolinsky, Y. L. Colson and M. W. Grinstaff, J. Control. Release, 2012, 159, 14-26.

62 R. S. Labow, E. Meek, L. A. Matheson and J. P. Santerre, Biomaterials, 2002, 23, 3969-3975.
63 W. Song, Z. Tang, M. Li, S. Lv, H. Yu, L. Ma, X. Zhuang, Y. Huang and X. Chen, Macromol. Biosc., 2012, 12, 1375-1383.

64 C. Yanga, Z. Xuea, Y. Liua, J. Xiaoa, J. Chena, L. Zhangb, J. Guoa and W. Lina, Mater. Sci. Eng. C, 2018, 84, 254-262.

65 J. Wang, B. M. Wang, and S. P. Schwendeman, J. Control. Release, 2002, 82, 289-307.

66 J. E. Bryant, M. P. Brown, R. R. Gronwall and K. A. Merritt, Equine Vet. J., 2000, 32, 233-238.

67 M. Donbrow and Y. Samuelov, J. Pharm. Pharmacol., 1980, 32, 463-470.

68 M. Gibaldi and S. Feldman, J. Pharm. Sci., 1967, 56, 12381242.

69 N. A. Peppas, Pharm. Acta Helv., 1985, 60, 110-111.

70 P.L. Ritger and N. A. Peppas, J. Control. Release, 1987, 5, 23-36.

71 R. Das and S. Pal, Colloids Surf. B., 2013, 110, 236-241.

72 R. W. Korsemeyer, R. Gurny, E. Doelker, P. Buri, and N. A. Peppas, Int. J. Pharm. 1983, 15, 25-35.

73 M. Kopcha, N. G. Lordi and K. J. Toja, J. Pharm. Pharmacol., 1991, 43, 382-387.

74 T. Higuchi, J. Pharm. Sci. 1961, 50, 874- 875.

75 A. W. Hixson and J. H. Crowell, Ind. Eng. Chem., 1931, 23, 923-931.

76 A. Thakur, S. Monga, and R. K. Wanchoo, Chem. Biochem. Eng. Q., 2014, 28, 105-115.

77 B. Tasdelen, N. K. Apohan, O. Guven and B. M. Baysal, J. Appl. Polym. Sci., 2004, 91, 911-915. 